\title{
Variational analysis of free-edge stress and displacement fields in general un-symmetric and thin-ply laminates under in-plane, bending and thermal loading \\ M. Hajikazemi", W. Van Paepegem \\ Department of Materials, Textiles and Chemical Engineering, Faculty of Engineering and Architecture, Ghent University, Technologiepark Zwijnaarde 903, Ghent, Belgium
}

\begin{abstract}
A variational approach based on the minimization of complementary energy is developed to determine accurately a complete solution for both free-edge stress and displacement distributions of a laminate with arbitrary lay-ups (possibly un-symmetric and made of thin plies) under combined in-plane, bending and thermal loading. The key idea is partitioning the total stresses/displacements in a laminate with free edges into unperturbed (without free edges) and unknown perturbation stresses/displacements caused by the presence of free edges. It enables the theory of variational stress-transfer to deal easily with both applied traction and displacement boundary conditions. A methodology is introduced to obtain displacement fields for a stress-based variational approach. The resulting stress and displacement fields exactly satisfy local equilibrium equations, strain-displacement relations together with all traction/displacement boundary and continuity conditions. By comparing the results with those obtained from the finite element method, the accuracy and computational efficiency of the developed model, is confirmed.
\end{abstract}

Keywords: A. Laminates; B. Stress concentrations; B. stress transfer; C. Analytical modelling.

\section{Introduction}

It is well known that edge effects in laminated composites may lead to unstable growth of ply cracks and delaminations [1-5]. In order to prevent/predict such damage mechanisms, it is essential that a reliable methodology is developed to determine accurately the three-dimensional (3D) stress/displacement states near free edges caused by the mismatch of elastic properties between layers. Therefore, the capability of interlaminar stress analysis in laminates with straight free edges has been a major concern and its understanding has evolved over decades, from very first approximate shear-lag analysis of Puppo and Evensen [6] in 1970s, to equivalent single-layer (ESL) models [7] and more accurate layer-wise (LW) approaches [8, 9]. It is very difficult to find a closed form solution for the 3D differential equations of elasticity describing the free-edge effect and satisfying the required traction free

\footnotetext{
"Corresponding Author, Tel: +32479659875, E-mail address: Mohammad.hajikazemi@ugent.be, Postal address: Technologiepark 903, 9052 Zwijnaarde, Ghent, Belgium.
} 
boundary conditions and the interface continuity conditions in laminates with general lay-ups. Thus, many methodologies have been introduced by making simplified assumptions about the kinematics of displacement fields (displacement-based theories based on the principle of minimum total potential energy [10]) or stress fields (stressbased theories based on the principle of minimum total complementary energy [11]) through the thickness of each ply (LW models) or through the thickness of the laminate (ESL models) to reduce the order of the problem to a 2D one. The reader is referred to Ref. [12-14] for an extensive literature review about the advances in this field.

Generally, LW displacement-based theories are simpler and can be easily linked to finite element methods to develop a design tool. Moreover, they can provide both stress and displacement fields. However, they cannot exactly satisfy the zero traction condition on free surfaces neither stress continuities between the layers, leading to a lower convergence rate which might be a concern for the free-edge problem. On the other hand, LW stress-based theories can satisfy exactly the traction boundary conditions and stress continuities between the layers which would lead to a more accurate and computationally efficient scheme.

Hashin [15] in 1985, first applied the LW stress-based variational theory to analyze a cracked cross-ply laminate under uniaxial tension. Since then, many authors have further enhanced both the accuracy and versatility of the variational approach to deal with ply cracking in more complex lay-ups and loading conditions (see Ref. [16-23]). Kassapoglou and Lagace [24] in 1986, independently and using a rather different methodology, implemented the variational approach to analyze approximately the stress concentrations near free edges under uniaxial loading. Kassapoglou [11] (whose approach is the closest to the one developed in the present paper) has extended this approach for combined loading cases and bending. In these models [11,24] exponential functions are assumed and the principle of minimum complementary energy is used to obtain expressions for the decay rates. Later, some authors have also considered the effects of thermal residual stresses [25] and bending modes of deformation [26]. Moreover, Rose and Herakovich [27] have considered more complete stress functions to increase the accuracy of the variational approach. A comprehensive literature review of recent developments in stress-based variational approaches can be found in Refs. $[12,14]$ and Refs. $[20,28]$ for the free-edge and ply cracking stress transfer analyses, respectively. The first limitation of the available LW stress-based variational models is that they have not made any attempts to obtain the corresponding displacement fields. However, it does not mean that these approaches cannot inherently generate the displacement fields. It is mainly due to this fact that the strain-displacement equations need not to be considered due to the implementation of the complementary energy principle. Therefore, only stress 
solutions are provided leading to an incomplete solution. Second, all of the available LW stress-based models akin to other methods introduced in this work, are aimed at eliminating the dependence of the stress state on the throughthickness coordinate of the laminate to make a system of ordinary differential equations as a result of energy minimization. Therefore, the accuracy of a developed method depends on the stress state assumed in each ply and how these assumptions can be relaxed. Some of the available LW free-edge variational models [25-27] will usually face a set of non-homogeneous ordinary differential equations. It is due to this fact that for implementation of the complementary energy principle, the assumed stress field must satisfy the applied traction loading conditions, a priori. Therefore, relaxing the assumptions in the stress field will lead to a large number of non-homogeneous differential equations which cannot be systematically solved. Due to the lack of a systematic way to formulate the equations and their solutions, it is difficult to develop a design tool based on these available variational models [2527] and thus, they usually do not manage to reproduce results obtained from very refined numerical methods (e.g. FEM) especially close to free edges. Moreover, although most of the experiments dealing with free-edge effect are under displacement loading conditions, the stress-based approaches are challenged when dealing with applied displacement loads.

In the current paper, a novel variational model is developed to overcome the mentioned drawbacks and to deal with the problem of free-edge interlaminar stress and displacement analysis in laminate strips with general lay-ups (possibly made of many thin plies) under in-plane, bending and uniform thermal loading conditions. The analysis takes into account the effects of thermal residual stresses [29]. The one single fundamental assumption is that the inplane transverse and shear stresses are linear through-thickness of each ply. Akin to the variational models developed for ply cracking [15-23], the total stresses/displacements in a composite with free edges are partitioned to unperturbed (without free edge) and perturbation stresses/displacements. Therefore, it is possible to consider the effects of applied thermo-mechanical loads in the unperturbed state leading to a system of homogeneous differential equations that can be solved using standard methods. Moreover, the differential equations are derived in a systematic way so that a design tool/software is developed by which the effects of assumptions in the assumed stress field can be relaxed by implementing a ply refinement technique [30]. The final results satisfy exactly the local stress equilibrium equations, both traction and displacement boundary and continuity conditions and minimize the total complementary energy. Moreover, the obtained displacement fields satisfy either exactly or in average sense the strain-displacement relations. The numerical results are compared to the available refined finite element results 

conditions showing very good agreement. The method is applied to a thin-ply laminate under a bending load to compare the stress transfer mechanisms in thin and typical ply composite laminates. A discussion is also made about the assumptions and accuracy of Pagano's approximate elasticity solution (Reissner variational principle) [34, 35], McCartney's stress transfer methodology [36-38] and the current variational approach to highlight the similarities and differences between these theories. It should be noted that the current model is an extension of a recently developed model by authors [39] which could only be applied to the analysis of symmetric laminates under in-plane loads.

\section{Theoretical Formulation}

Consider a general laminate with arbitrary stacking sequence as shown in Fig. 1. A Cartesian coordinate system, located at the center of the laminate, is used where the $\mathrm{x}, \mathrm{y}$ and $\mathrm{z}$ coordinates specify the in-plane axial (loading), inplane transverse (normal to free edges) and through-thickness directions, respectively. The locations of N-1 interfaces between the plies are denoted by $\mathrm{z}=\mathrm{z}_{\mathrm{i}} ; \mathrm{i}=1,2 \ldots \mathrm{N}-1$. The lower and upper external surfaces are defined by $\mathrm{z}=\mathrm{z}_{0}=-\mathrm{h} / 2$ and by $\mathrm{z}=\mathrm{z}_{\mathrm{N}}=\mathrm{h} / 2$, where $\mathrm{h}$ is the total thickness of the laminate. Moreover, the thickness of the $\mathrm{i}^{\text {th }}$ ply is denoted by $h_{i}=z_{i}-z_{i-1}$. The angle $\theta_{i}$ defines the orientation of $i^{\text {th }}$ ply, measured counter clockwise between the $\mathrm{x}$-axis and the fiber direction of the ply. The laminate is long in $x$ direction $(\mathrm{L}>>\mathrm{W})$ where $2 \mathrm{~L}$ and $2 \mathrm{~W}$ are, respectively, the length and width of the laminate (see Fig. 1).

The in-plane, bending and thermal loads are applied, respectively, in the form of a uniform axial strain $\varepsilon_{x x}$, an axial curvature with respect to the mid-plane $(\mathrm{z}=0) \kappa_{x x}$ and a temperature difference $\Delta \mathrm{T}$. In the context of classical laminated plate theory (CLPT), for a wide and long laminate without any free edges under the assumed loading condition, the only nonzero stress terms are, $\sigma_{x x}^{0(i)}, \sigma_{y y}^{0(i)}, \sigma_{x y}^{0(i)}$, where the superscript 0 specifies the infinite laminate and the superscript (i), $\mathrm{i}=1,2, \ldots, \mathrm{N}$, specifies the number of the ply. It is noted that the terms "unperturbed laminate" or "infinite laminate" refer to a long and wide laminate without having any free edges. Then, it is assumed that the stresses in the $\mathrm{i}^{\text {th }}$ ply of the laminate with free edges $\left(\sigma_{m n}^{i}\right)$ are written as a superposition of the stresses in the unperturbed state $\left(\sigma_{m n}^{0(i)}\right)$ and some perturbation stress functions $\left(\sigma_{m n}^{p(i)}\right)$ appearing due to the presence of the free edges. 


$$
\sigma_{m n}^{i}(y, z)=\sigma_{m n}^{0(i)}(y, z)+\sigma_{m n}^{p(i)}(y, z)
$$

where $m, n=x, y, z$.

Our goal is to find stress and displacement fields which point-wisely satisfy the stress equilibrium equations $\sigma_{m n, n}^{i}=0$ together with the following stress-strain-displacement relations:

$$
\begin{gathered}
\varepsilon_{x x}^{i} \equiv \frac{\partial u_{i}}{\partial x}=S_{11}^{i} \sigma_{x x}^{i}+S_{12}^{i} \sigma_{y y}^{i}+S_{13}^{i} \sigma_{z z}^{i}+S_{16}^{i} \sigma_{x y}^{i}+\alpha_{1}^{i} \Delta T \\
\varepsilon_{y y}^{i} \equiv \frac{\partial v_{i}}{\partial y}=S_{12}^{i} \sigma_{x x}^{i}+S_{22}^{i} \sigma_{y y}^{i}+S_{23}^{i} \sigma_{z z}^{i}+S_{26}^{i} \sigma_{x y}^{i}+\alpha_{2}^{i} \Delta T \\
\varepsilon_{z z}^{i} \equiv \frac{\partial w_{i}}{\partial z}=S_{13}^{i} \sigma_{x x}^{i}+S_{23}^{i} \sigma_{y y}^{i}+S_{33}^{i} \sigma_{z z}^{i}+S_{36}^{i} \sigma_{x y}^{i}+\alpha_{3}^{i} \Delta T \\
2 \varepsilon_{y z}^{i} \equiv \frac{\partial v_{i}}{\partial z}+\frac{\partial w_{i}}{\partial y}=S_{44}^{i} \sigma_{y z}^{i}+S_{45}^{i} \sigma_{x z}^{i} \\
2 \varepsilon_{x z}^{i} \equiv \frac{\partial u_{i}}{\partial z}+\frac{\partial w_{i}}{\partial x}=S_{45}^{i} \sigma_{y z}^{i}+S_{55}^{i} \sigma_{x z}^{i} \\
2 \varepsilon_{x y}^{i} \equiv \frac{\partial u_{i}}{\partial y}+\frac{\partial v_{i}}{\partial x}=S_{16}^{i} \sigma_{x x}^{i}+S_{26}^{i} \sigma_{y y}^{i}+S_{36}^{i} \sigma_{z z}^{i}+S_{66}^{i} \sigma_{x y}^{i}+\alpha_{6}^{i} \Delta T
\end{gathered}
$$

where $\mathrm{u}_{\mathrm{i}}, \mathrm{v}_{\mathrm{i}}$ and $\mathrm{w}_{\mathrm{i}}$ denote the displacement components for the $\mathrm{i}^{\text {th }}$ layer in the $\mathrm{x}, \mathrm{y}$ and $\mathrm{z}$ directions, respectively, and $\varepsilon_{x x}^{i}, \varepsilon_{y y}^{i}$ etc., represent the strain components. In addition, the terms $S_{k l}^{i}$ and $\alpha_{k}^{i}$ specify the compliance and thermal expansion coefficients of the $\mathrm{i}^{\text {th }}$ layer, respectively. Moreover, the stress and displacement components have to satisfy some boundary and interface continuity conditions, as follows:

1. Zero traction condition on the top and bottom external surfaces $\mathrm{z}= \pm \mathrm{h} / 2: \sigma_{x z}=\sigma_{y z}=\sigma_{z z}=0$.

2. Continuity of stresses and displacements at the interfaces between the ply elements $\left(z=z_{i}, i=1,2, \ldots, N-1\right)$ : $\sigma_{x z}^{i}=\sigma_{x z}^{i+1}, \sigma_{y z}^{i}=\sigma_{y z}^{i+1}, \sigma_{z z}^{i}=\sigma_{z z}^{i+1}$ and $u_{i}=u_{i+1}, v_{i}=v_{i+1}, w_{i}=w_{i+1}$.

3. Zero traction condition on the free edges at $\mathrm{y}= \pm \mathrm{W}, \mathrm{i}=1,2, \ldots, \mathrm{N}: \sigma_{y y}^{i}=\sigma_{y z}^{i}=\sigma_{x y}^{i}=0$.

\subsection{Stress field construction}


For a long laminate $(\mathrm{L}>>\mathrm{W})$, all stresses will be independent of the $\mathrm{x}$ in the coordinate where the straight free edges are parallel to the $\mathrm{x}$-axis. The single fundamental assumption of this analysis is that the in-plane transverse and shear perturbation stresses of each ply are linear in z but vary arbitrarily along the y-axis, as follows:

$$
\sigma_{y y}^{p(i)}(y, z)=\frac{1}{h_{i}}\left(p_{i}(y) \zeta_{i}+p_{i}^{*}(y)\right), \sigma_{x y}^{p(i)}(y, z)=\frac{1}{h_{i}}\left(q_{i}(y) \zeta_{i}+q_{i}^{*}(y)\right), \zeta_{i}=\frac{z-z_{i-1}}{z_{i}-z_{i-1}}
$$

where $p_{i}(y), p_{i}^{*}(y), q_{i}(y)$ and $q_{i}^{*}(y)$ are unknown functions of y only. The remaining stress components will be derived by satisfying the stress equilibrium equations $\sigma_{m n, n}^{i}=0$, as follows:

$$
\begin{gathered}
\sigma_{y z}^{p(i)}(y, z)=\frac{1}{2} p_{i}^{\prime}(y)\left(1-\zeta_{i}^{2}\right)+\left(1-\zeta_{i}\right) p_{i}^{*^{\prime \prime}}(y)-F_{1}^{i}(y), \\
\sigma_{x z}^{p(i)}(y, z)=\frac{1}{2} q_{i}^{\prime}(y)\left(1-\zeta_{i}^{2}\right)+\left(1-\zeta_{i}\right) q_{i}^{*^{\prime}}(y)-F_{2}^{i}(y), \\
\sigma_{z z}^{p(i)}(y, z)=\frac{h_{i}}{2} p_{i}^{\prime \prime}(y)\left(\frac{\zeta_{i}^{3}}{3}-\zeta_{i}+\frac{2}{3}\right)+h_{i} p_{i}^{* \prime \prime}(y)\left(\frac{\zeta_{i}^{2}}{2}-\zeta_{i}+\frac{1}{2}\right)+h_{i}\left(\zeta_{i}-1\right) F_{1}^{i^{\prime}}(y)+F_{3}^{i}(y),
\end{gathered}
$$

where

$$
\begin{gathered}
F_{1}^{i}(y)=\sum_{j=1}^{i}\left(\frac{p_{j}^{\prime}(y)}{2}+p_{j}^{* \prime}(y)\right), \quad F_{2}^{i}(y)=\sum_{j=1}^{i}\left(\frac{q_{j}^{\prime}(y)}{2}+q_{j}^{* \prime}(y)\right) \\
F_{3}^{i}(y)=\sum_{j=1}^{i} h_{j}\left(-\left(\frac{p_{j}^{\prime \prime}(y)}{3}+\frac{p_{j}^{* \prime \prime}(y)}{2}\right)+\sum_{k=1}^{j}\left(\frac{p_{k}^{\prime \prime}(y)}{2}+p_{k}^{* \prime \prime}(y)\right),\right.
\end{gathered}
$$

and primes denote derivatives with respect to y. It is noted that to derive the equations (9)-(12), use has been made of integrating stress equilibrium equations $\sigma_{m n, n}^{i}=0$, with satisfaction of traction continuities at the interfaces between plies.

It should be noted that the axial strain $\varepsilon_{x x}$ and curvature $\kappa_{x x}$ are already defined as input loading parameters, thus, the perturbation in-plane axial stress will be defined in terms of the other perturbation stress terms using Eq. (2), as follows: 
Before using the principle of minimum complementary energy to find the optimal perturbation functions, the constructed admissible stress fields should balance the traction boundary conditions $N_{y y}=M_{y y}=N_{x y}=M_{x y}=0$ which assert the following inter-relationships among perturbation functions:

$$
\begin{aligned}
& \sum_{i=1}^{N}\left(\frac{p_{i}(y)}{2}+p_{i}^{*}(y)\right)=0, \sum_{i=1}^{N}\left(p_{i}(y)\left(\frac{h_{i}}{3}+\frac{z_{i-1}}{2}\right)+p_{i}^{*}(y)\left(\frac{h_{i}}{2}+z_{i-1}\right)\right)=0, \\
& \sum_{i=1}^{N}\left(\frac{q_{i}(y)}{2}+q_{i}^{*}(y)\right)=0, \sum_{i=1}^{N}\left(q_{i}(y)\left(\frac{h_{i}}{3}+\frac{z_{i-1}}{2}\right)+q_{i}^{*}(y)\left(\frac{h_{i}}{2}+z_{i-1}\right)\right)=0 .
\end{aligned}
$$

The above equations ensure that the out-of-plane shear and normal stresses $\left(\sigma_{\mathrm{xz}}, \sigma_{\mathrm{yz}}, \sigma_{\mathrm{zz}}\right)$ are automatically zero on $\mathrm{z}$ $= \pm \mathrm{h} / 2$. Finally, based on one fundamental assumption that the in-plane transverse and shear perturbation stresses of each ply are linear in $z$, the admissible stress fields represented by equations (8)-(14) point-wisely satisfy stress equilibriums, through-thickness traction boundary conditions and interface continuity conditions for any perturbation functions $p_{i}(y), p_{i}^{*}(y), q_{i}(y)$ and $q_{i}^{*}(y), \mathrm{i}=1 \ldots \mathrm{N}$. Besides, Eq. (15) provides four relations among the perturbation stress functions to balance the applied traction boundary conditions and thus, the number of perturbation functions that must be evaluated, is $4(\mathrm{~N}-1)$. It is noted that by superposition of stresses into the unperturbed and perturbation stresses, the effects of applied traction and displacement boundary conditions as well as uniform temperature change are already considered in the analysis of the unperturbed laminate (CLPT analysis) and will be taken into account later using the boundary conditions at traction free edges that will be discussed in detail.

\subsection{Complementary energy minimization}

The complementary energy will be minimized to obtain the perturbation stress functions. The total complementary energy $\mathrm{U}_{\text {com }}$ of a laminate subject to mixed traction/displacement boundary conditions including the effects of thermal residual stresses can be written as follows [40]: 
where $U_{c o m}^{0}$ is the complementary energy of the unperturbed state (laminate without free edges), which does not contribute to the variation. In addition, $S$ is the compliance tensor and V represents the region occupied by the laminate. As the variation of the unperturbed complementary energy is zero $\left(\partial U_{c o m}^{0} \equiv 0\right)$, it is sufficient to minimize the perturbation complementary energy functional $\left(U^{P}\right)$. The perturbation complementary energy functional $\left(U^{p}\right)$ will be minimized over the region of width $2 W$ bounded by two free edges, such that $|y| \leq W$ and $|z| \leq h / 2$,

$$
U^{p}=\sum_{i=1}^{N}\left(\int_{-W}^{W} \int_{z_{i-1}}^{z_{i}} \frac{1}{2}\left\{\sigma^{p(i)}\right\}^{T}\left[S^{(i)}\right]\left\{\sigma^{p(i)}\right\} d z d y\right),
$$

where $\left[S^{(i)}\right]$ is the compliance matrix of the $\mathrm{i}^{\text {th }}$ layer in the global coordinate system.

Substituting the perturbation stresses from (Eqs. (8)-(14)) and the global compliance matrices into Eq. (17) together with integrating over $\mathrm{z}$, the perturbation complementary energy can be written as follows, in terms of independent unknown stress perturbation functions:

$$
U^{P}=\int_{-W}^{W} F\left(y,\{p\},\left\{p^{*}\right\},\left\{p^{\prime \prime}\right\},\left\{p^{* \prime \prime}\right\},\{q\},\left\{q^{*}\right\},\left\{p^{\prime}\right\},\left\{p^{* \prime}\right\},\left\{q^{\prime}\right\},\left\{q^{* \prime}\right\}\right) d y,
$$

where the vectors $\{p\}_{(N-1) \times 1}$, etc. are vectors of independent unknown perturbation functions and the functional $\mathrm{F}$ is defined in Appendix A.

It should be noted that minimization of the complementary energy leads to the Euler-Lagrange equations [18]. The Euler-Lagrange equations for the functional defined in Eq. (18) are, as follows:

$$
\begin{gathered}
\frac{\partial F}{\partial\{p\}}-\frac{d}{d y}\left(\frac{\partial F}{\partial\left\{p^{\prime}\right\}}\right)+\frac{d^{2}}{d y^{2}}\left(\frac{\partial F}{\partial\left\{p^{\prime \prime}\right\}}\right)=0, \\
\frac{\partial F}{\partial\left\{p^{*}\right\}}-\frac{d}{d y}\left(\frac{\partial F}{\partial\left\{p^{* \prime}\right\}}\right)+\frac{d^{2}}{d y^{2}}\left(\frac{\partial F}{\partial\left\{p^{* \prime \prime}\right\}}\right)=0,
\end{gathered}
$$


Applying the above equations to the functional (F) defined in Eqs. (18) and (A.1), The governing differential equations can be written as follows:

$$
\begin{gathered}
{\left[T_{1}\right]\left\{p^{\prime \prime \prime}\right\}+\left[T_{2}\right]\left\{p^{\prime \prime}\right\}+\left[T_{3}\right]\{p\}+\left[T_{4}\right]\left\{p^{* * \prime \prime}\right\}+\left[T_{5}\right]\left\{p^{* * \prime}\right\}+\left[T_{6}\right]\left\{p^{*}\right\}+} \\
{\left[T_{7}\right]\left\{q^{\prime \prime}\right\}+\left[T_{8}\right]\{q\}+\left[T_{9}\right]\left\{q^{* \prime \prime}\right\}+\left[T_{10}\right]\left\{q^{*}\right\}=0,} \\
{\left[T_{4}\right]^{T}\left\{p^{\prime \prime \prime \prime}\right\}+\left[T_{5}\right]^{T}\left\{p^{\prime \prime}\right\}+\left[T_{6}\right]^{T}\{p\}+\left[T_{11}\right]\left\{p^{* * \prime \prime}\right\}+\left[T_{12}\right]\left\{p^{* \prime \prime}\right\}+\left[T_{13}\right]\left\{p^{*}\right\}+} \\
{\left[T_{14}\right]\left\{q^{\prime \prime}\right\}+\left[T_{15}\right]\{q\}+\left[T_{16}\right]\left\{q^{* \prime \prime}\right\}+\left[T_{17}\right]\left\{q^{*}\right\}=0,} \\
{\left[T_{7}\right]^{T}\left\{p^{\prime \prime}\right\}+\left[T_{8}\right]^{T}\{p\}+\left[T_{14}\right]^{T}\left\{p^{* * \prime}\right\}+\left[T_{15}\right]^{T}\left\{p^{*}\right\}+} \\
{\left[T_{18}\right]\left\{q^{\prime \prime}\right\}+\left[T_{19}\right]\{q\}+\left[T_{20}\right]\left\{q^{* \prime \prime}\right\}+\left[T_{21}\right]\left\{q^{*}\right\}=0,} \\
{\left[T_{9}\right]^{T}\left\{p^{\prime \prime}\right\}+\left[T_{10}\right]^{T}\{p\}+\left[T_{16}\right]^{T}\left\{p^{* \prime \prime}\right\}+\left[T_{17}\right]^{T}\left\{p^{*}\right\}+} \\
{\left[T_{20}\right]^{T}\left\{q^{\prime \prime}\right\}+\left[T_{21}\right]^{T}\{q\}+\left[T_{22}\right]\left\{q^{* \prime \prime}\right\}+\left[T_{23}\right]\left\{q^{*}\right\}=0,}
\end{gathered}
$$

where the $\left[T_{i}\right]$ matrices, $\mathrm{i}=1 \ldots 23$, are all obtained analytically and given in Appendix B.

The Eqs. (23)-(26) are a coupled system of homogeneous fourth order ordinary differential equations with constant coefficients for which so many solution methods have been developed. The reader is referred to Ref. [19, 20] to find details about solving these differential equations.

After solving the differential equations (Eqs. (23)-(26)), the boundary conditions should be applied to provide a unique solution. The above differential equations require, in total, $12(\mathrm{~N}-1)$ boundary conditions.

The stress free conditions for each ply on the free edges $y= \pm W$, can be written

$$
\begin{aligned}
& \sigma_{y y}^{i}( \pm W, z)=0 \Rightarrow \sigma_{y y}^{p(i)}( \pm W, z)=-\sigma_{y y}^{0(i)}(z), \\
& \sigma_{x y}^{i}( \pm W, z)=0 \Rightarrow \sigma_{x y}^{p(i)}( \pm W, z)=-\sigma_{x y}^{0(i)}(z),
\end{aligned}
$$




$$
\sigma_{y z}^{i}( \pm W, z)=0 \Rightarrow \sigma_{y z}^{p(i)}( \pm W, z)=0
$$

Considering the perturbation stresses defined in Eqs. (8) and (9), the above equations will provide 12 (N-1) boundary conditions in terms of independent perturbation functions $\mathrm{p}_{\mathrm{i}}(\mathrm{y}), \mathrm{p}_{\mathrm{i}}^{*}(\mathrm{y}), \mathrm{p}_{\mathrm{i}}^{\prime}(\mathrm{y}), \mathrm{p}_{\mathrm{i}}^{\prime *}(\mathrm{y}), \mathrm{q}_{\mathrm{i}}(\mathrm{y})$ and $\mathrm{q}_{\mathrm{i}}^{*}(\mathrm{y})$, as needed.

It can be seen in Eq. (16) that by partitioning the total stresses into the initial and perturbation stresses, the effect of thermal residual stresses on the complementary energy can be evaluated completely by a thermoelasticity analysis of the composite without free edge only (unperturbed state) which can be readily done using a simple analysis based on the CLPT. Indeed, the effects of the actual mechanical and thermal loads (already considered in the unperturbed state) come through the constant fields (see Eqs. (27)-(29)) in the boundary conditions at traction free surfaces. Therefore, it can be concluded that the effects of residual stresses caused by humidity can be similarly taken into account by analogy with thermal residual stresses. To do so, it is enough to consider all hygro-thermal residual stresses in the analysis of the unperturbed state while implementing a CLPT analysis and their effects will be automatically reflected in Eqs. (27)-(29).

\subsection{Displacement fields}

Due to the implementation of the minimum complementary energy principle, the variational model needs only stress components to determine the solution leading to an incomplete elasticity solution. However, it is well known [41] that among the admissible stress fields that satisfy stress equilibrium equations together with traction boundary conditions, the one that leads to a compatible set of displacements minimizes the total complementary energy. Beyond the scope of the current approach, McCartney [36, 37] has developed a stress transfer model for cracked cross-ply laminates based on the assumption of the Generalized Plane Bending (GPB) condition. Here, we will extend this methodology to derive corresponding displacement fields in a general laminate for the variational model based on the admissible stress fields (Eq. (8)-(14)).

The laminate is considered to be under generalized plane bending conditions where the displacement field in each ply (i) has the following form

$$
\begin{aligned}
& u_{i}=\left(\varepsilon_{x x}+z \kappa_{x x}\right) x+\left(\varepsilon_{x y}^{0}+z \kappa_{x y}^{0}\right) y+g_{1}^{i}(y, z), \\
& v_{i}=\left(\varepsilon_{y y}^{0}+z \kappa_{y y}^{0}\right) y+\left(\varepsilon_{x y}^{0}+z \kappa_{x y}^{0}\right) x+g_{2}^{i}(y, z),
\end{aligned}
$$




$$
w_{i}=-\frac{1}{2} \kappa_{x x} x^{2}-\frac{1}{2} \kappa_{y y}^{0} y^{2}-\kappa_{x y}^{0} x y+g_{3}^{i}(y, z)
$$

where $\varepsilon_{y y}^{0}, 2 \varepsilon_{x y}^{0}, \kappa_{y y}^{0}, 2 \kappa_{x y}^{0}$ are, respectively, in-plane transverse strain, in-plane shear strain, transverse and shear curvatures of the infinite laminate (without free edges) with respect to the mid-plane $(z=0)$ when the laminate is under the input loading parameters $\varepsilon_{x x}, \kappa_{x x}$ and $\Delta T$. It is noted that all above parameters can be easily obtained using a simple analysis based on the CLPT. It is also noted that the functions $g_{k}^{i}, \mathrm{k}=1,2,3, \mathrm{i}=1 \ldots \mathrm{N}$, that are to be determined, are all independent of x. It is obvious that the axial displacement field (Eq. (30)) automatically satisfies Eq. (2), (see Eqs. (13) and (14)). The stress/strain relations (3), (4) and (7) may then be written in the following reduced form on eliminating the stress component $\sigma_{x x}^{i}$ using (13)-(14)

$$
\begin{gathered}
\varepsilon_{y y}^{i} \equiv \frac{\partial v_{i}}{\partial y}=\bar{S}_{22}^{i} \sigma_{y y}^{i}+\bar{S}_{23}^{i} \sigma_{z z}^{i}+\bar{S}_{26}^{i} \sigma_{x y}^{i}+\bar{\alpha}_{2}^{i} \Delta T, \\
\varepsilon_{z z}^{i} \equiv \frac{\partial w_{i}}{\partial z}=\bar{S}_{23}^{i} \sigma_{y y}^{i}+\bar{S}_{33}^{i} \sigma_{z z}^{i}+\bar{S}_{36}^{i} \sigma_{x y}^{i}+\bar{\alpha}_{3}^{i} \Delta T, \\
2 \varepsilon_{x y}^{i} \equiv \frac{\partial u_{i}}{\partial y}+\frac{\partial v_{i}}{\partial x}=\bar{S}_{26}^{i} \sigma_{y y}^{i}+\bar{S}_{36}^{i} \sigma_{z z}^{i}+\bar{S}_{66}^{i} \sigma_{x y}^{i}+\bar{\alpha}_{6}^{i} \Delta T,
\end{gathered}
$$

where the reduced forms of compliances $\bar{S}_{m n}^{i}$ are defined in Appendix C. It then follows from Eqs. (8), (11), (12) and (34) that, for $0 \leq \zeta_{i} \leq 1$ and $i=1 \ldots \mathrm{N}$,

$$
\begin{aligned}
& w_{i}=-\frac{1}{2} \kappa_{x x} x^{2}-\frac{1}{2} \kappa_{y y}^{0} y^{2}-\kappa_{x y}^{0} x y+h_{i} \int_{0}^{\zeta_{i}} \varepsilon_{z z}^{0(i)} d \zeta+W_{i}(y) \\
& +h_{i}^{2} \bar{S}_{33}^{i}\left[\left(\frac{\zeta_{i}^{4}}{24}-\frac{1}{4} \zeta_{i}^{2}+\frac{1}{3} \zeta_{i}\right) p_{i}^{\prime \prime}(y)+\frac{\left(\zeta_{i}-1\right)^{3}}{6} p_{i}^{* \prime \prime}(y)+\left(\frac{\zeta_{i}^{2}}{2}-\zeta_{i}\right) F_{1}^{i^{\prime}}(y)+\frac{\zeta_{i}}{h_{i}} F_{3}^{i}(y)\right] \\
& +\zeta_{i}\left(\bar{S}_{23}^{i} p_{i}^{*}(y)+\bar{S}_{36}^{i} q_{i}^{*}(y)\right)+\frac{\zeta_{i}^{2}}{2}\left(\bar{S}_{23}^{i} p_{i}(y)+\bar{S}_{36}^{i} q_{i}(y)\right)
\end{aligned}
$$

where $W_{i}(y)$ arises from the integration over $\mathrm{z}$ and will be defined later in Appendix D. Moreover, $\varepsilon_{z z}^{0(i)}$ is the outof-plane strain in the $\mathrm{i}^{\text {th }}$ ply of the unperturbed laminate (without free edges).

It follows from Eqs. (5), (9), (10) and (36) that, for $0 \leq \zeta_{i} \leq 1$ and $i=1 \ldots \mathrm{N}$, 


$$
\begin{aligned}
& v_{i}=\left(\varepsilon_{y y}+z \kappa_{y y}^{0}\right) y+\left(\varepsilon_{x y}+z \kappa_{x y}^{0}\right) x-h_{i} \zeta_{i} W_{i}^{\prime}(y)+V_{i}(y) \\
& -\frac{h_{i}^{3} \bar{S}_{33}^{i}}{24}\left[\left(\frac{\zeta_{i}^{5}}{5}-2 \zeta_{i}^{3}+4 \zeta_{i}^{2}\right) p_{i}^{\prime \prime \prime}(y)+\left(\zeta_{i}-1\right)^{4} p_{i}^{* *^{\prime \prime \prime}}(y)+\left(4 \zeta_{i}^{3}-12 \zeta_{i}^{2}\right) F_{1}^{i^{\prime \prime}}(y)+\frac{12 \zeta_{i}^{2}}{h_{i}} F_{3}^{i^{\prime}}(y)\right] \\
& +\frac{h_{i} \zeta_{i}}{2}\left[p_{i}^{* \prime}(y)\left(2 S_{44}^{i}-\zeta_{i}\left(\bar{S}_{23}^{i}+S_{44}^{i}\right)\right)+q_{i}^{* \prime}(y)\left(2 S_{45}^{i}-\zeta_{i}\left(\bar{S}_{36}^{i}+S_{45}^{i}\right)\right)-2 S_{45}^{i} F_{2}^{i}(y)-2 S_{44}^{i} F_{1}^{i}(y)\right] \\
& +\frac{h_{i} \zeta_{i}}{2}\left[p_{i}^{\prime}(y)\left(S_{44}^{i}-\frac{\zeta_{i}^{2}}{3}\left(\bar{S}_{23}^{i}+S_{44}^{i}\right)\right)+q_{i}^{\prime}(y)\left(S_{45}^{i}-\frac{\zeta_{i}^{2}}{3}\left(\bar{S}_{36}^{i}+S_{45}^{i}\right)\right)\right],
\end{aligned}
$$

where $V_{i}(y)$, arising from the integration over $\mathrm{z}$, is defined in Appendix D.

Similarly from Eq. (6), (9), (10) and (36) that, for $0 \leq \zeta_{i} \leq 1$ and $\mathrm{i}=1 \ldots \mathrm{N}$,

$$
\begin{aligned}
& u_{i}=\left(\varepsilon_{x x}+z \kappa_{x x}\right) x+\left(\varepsilon_{x y}^{0}+z \kappa_{x y}^{0}\right) y+U_{i}(y) \\
& +h_{i}\left(-\frac{\zeta_{i}^{2}}{2}+\zeta_{i}\right)\left[s_{45}^{i} p_{i}^{* \prime}(y)+s_{55}^{i} q_{i}^{*^{\prime}}(y)\right]-h_{i} \zeta_{i}\left[s_{45}^{i} F_{1}^{i}(y)+s_{55}^{i} F_{2}^{i}(y)\right] \\
& +h_{i}\left(-\frac{\zeta_{i}^{3}}{6}+\frac{\zeta_{i}}{2}\right)\left[s_{45}^{i} p_{i}^{\prime}(y)+s_{55}^{i} q_{i}^{\prime}(y)\right],
\end{aligned}
$$

where $U_{i}(y)$, arising from the integration over z, is defined in Appendix D.

It is noted that the expressions derived for the stress and displacement components satisfy exactly the stress equilibrium equations $\sigma_{m n, n}^{i}=0$, together with the stress-strain relations (2), (4)-(6). In addition, the displacement and stress fields satisfy all the interface continuity and boundary conditions. The approach would lead to an exact elasticity solution if the stress and displacement components could locally satisfy the stress-strain relations (3) and (7), as well. However, it is impossible to exactly satisfy these two equations because of the assumptions made on the dependency of the in-plane stresses to z-direction (linear in z, Eq. (8)). Instead, we have minimized the complementary energy and it is shown by Rosen [41] that of all stress fields which satisfy equilibrium throughout the region and boundary conditions on portions of the surface over which tractions are prescribed, the set that yields a compatible set of displacements minimizes the complementary energy. It can be shown that the obtained displacement and stress fields satisfy Eqs. (3) and (7) in an average sense through the thickness of each layer and it was checked in computer code and has been found to be satisfied by input data in all considered cases. Beyond the scope of the current paper, Pagano [34, 35] and McCartney [36, 37] have developed two stress transfer models for ply cracking in general cross-ply laminates based on, respectively, Reissner energy principle and average 
Table. 1: Material properties of unidirectional plies used in this investigation.

\begin{tabular}{ccccccccc} 
Set of & $E_{A}$ & $\begin{array}{c}E_{T} \\
(G P a)\end{array}$ & $\begin{array}{c}G_{A} \\
(G P a)\end{array}$ & $\begin{array}{c}G_{T} \\
(G P a)\end{array}$ & $v_{A}$ & $v_{A}$ & $\begin{array}{c}\alpha_{A} \\
\left(10^{-6} /{ }^{0} C\right)\end{array}$ & $\begin{array}{c}\alpha_{T} \\
\left(10^{-6} /{ }^{0} C\right)\end{array}$ \\
\hline Materials & $(G P a)$ & & & & & & & 28.8 \\
\hline$\# 1$ & 137.9 & 14.48 & 5.86 & 5.86 & 0.21 & 0.21 & 0.36 & -
\end{tabular}

First, an un-symmetric [0/90/45/90] laminate (made of the material set \#1) under a pure bending load $\left(\mathrm{M}_{\mathrm{xx}}\right)$, is considered. It should be noted that the input loading parameters in the current model are in the form of applied axial 
strain $\varepsilon_{x x}$ and curvature $\kappa_{x x}$ which are the same for the perturbed and unperturbed cases (it is noted that $N_{y y}=N_{x y}=M_{y y}=M_{x y}=0$ are other loading parameters which have always zero values). Therefore, a pure $M_{x x}$ bending loading condition is approximated by a combination of applied axial strain and curvature for the case of unperturbed state. This condition can be easily obtained using a simple CLPT analysis. The laminate has the width $2 \mathrm{~W}=4 \mathrm{~h}$ where, as already mentioned, $\mathrm{h}=4 \mathrm{t}^{\mathrm{ply}}$ is the thickness of the laminate (see Fig. 1). Mathematical software is developed to consider general laminates with ply refinement to improve the accuracy of predictions and ensure that the results are converged. Therefore, each ply was first divided into 6 elements of equal thickness. Further, the ply elements adjacent to all the interfaces were sub-divided in half, two times to take into account the high stress concentrations at the interfaces between plies near free edges. Figs. $2 \mathrm{a}$ and $2 \mathrm{~b}$ depict the through-width distribution of normalized out-of-plane normal $\frac{\sigma_{z z} \times h^{2}}{2 M_{x x}}$ and shear $\frac{\sigma_{y z} \times h^{2}}{2 M_{x x}}$ stresses, respectively, at the interface between the $90^{\circ}$ and $45^{\circ}$ plies $\left(\mathrm{z}=0\right.$, laminate mid-plane) and at the interface between the $45^{\circ}$ and $90^{\circ}$ plies $(\mathrm{z}=\mathrm{h} / 4$, upper interface). The results are compared with FEM results reported in Ref. [31]. It can be seen that there is very good agreement between the results of the variational approach and FEM [31] for an un-symmetric laminate under bending loads even close to the free edges. It can be also seen (see $\sigma_{y z}$ distribution in Figs. $2 \mathrm{a}$ and $\mathrm{b}$ ) that FEM cannot satisfy the zero traction conditions at free edges while the stress fields obtained based on the variational approach exactly satisfy zero traction boundary conditions at free edges. On the other hand, the run time of the variational approach for this case on an Intel Core i3 $(2.27 \mathrm{GHz})$ processor is less than one second whereas the computational time of the FEM model is reported to be 540 seconds [31].

Second, two $[ \pm 10]_{s}$ and $[ \pm 20]_{s}$ symmetric laminates (made of the material set \#2) under a uniform in-plane axial strain $\varepsilon_{x x}$ are considered. The laminates have the width $2 \mathrm{~W}=20 \mathrm{~mm}$ and the thickness of each ply is assumed to be $\mathrm{t}^{\mathrm{ply}}=0.19 \mathrm{~mm}$. To further check the accuracy of the developed approach, the results are compared with the refined FEM results of Ref. [30] which are reported in regions very close to the free edges. It is noted that the FEM meshes are very refined near the free edges where elements' size is less than 1 micron [30] to ensure having converged results. The variational approach is applied to this problem with three different levels of ply refinement. First, each ply is only divided into 2 elements of equal thickness $(n=2)$. Second, each ply is divided into 8 elements of equal thickness $(\mathrm{n}=8)$. Third, after dividing each ply into 8 elements of equal thickness, the elements adjacent to 
all interfaces have been further divided in half, four times (Double refined). Figs. 3a and $3 b$ depict the transverse distribution of the normalized interlaminar shear $\frac{\sigma_{x z}}{\varepsilon_{x x} E_{x x}}$ stresses ( $E_{x x}$ is the axial stiffness of the laminate) very close to the free edge at the $\theta /-\theta$ interfaces of $[ \pm 10]_{s}$ and $[ \pm 20]_{s}$ laminates, respectively. It can be clearly seen that for both lay-ups, $5 \%$ of a ply thickness far from the free edge, the results obtained from the FEM and variational approach (with different level of ply refinements) are in excellent agreement. It shows that the current variational approach using a very small amount of ply refinement $(n=2)$ can provide accurate information about the stress state. On the other hand, there is rather a large discrepancy between the refined variational (double refined) and FEM solutions, very close to the free edge. It can be seen that the variational approach with ply refinement $(n=8)$ has the same accuracy as refined 3D FEM. It has been shown by Wang and Choi $[44,45]$ that the state of stress close to free edges is generally singular and inherently three-dimentional where the strength of the boundary-layer (free-edge) singularity depends on elastic properties and laminate lay-up. In the current formulation, the effects of this boundary-layer are considered by the implementation of a large amount of ply refinements leading to very large eigenvalues in the solutions of the governing differential equations. Using the refined meshes near free edges and interfaces in FEM is also an attempt to capture the effects of this singularity. However, solution convergence in elasticity problems with singularities by conventional displacement-based finite elements is independent of refinement of meshes and increases in the order of element formulations [46]. Moreover, in the evaluation of interlaminar stresses along the interfaces, FEM needs extrapolation schemes, which by themselves may introduce numerical errors in the final results while in the current approach interlaminar stresses are directly obtained without requiring any extrapolations. Moreover, as discussed by Bauld et al. [47], a finite element node coinciding with the interface corner (like a node at the edge locations and on the interface between the plies), receives average contributions from the finite elements on either side of the interface. In a finite element solution a stress-free boundary condition translates into a nodal force-free boundary condition. Therefore, setting the nodal force at the interface cornr equal to zero is, in some sense, an averaging procedure. The finite element method relies on the virtual work principle to establish a static equivalence between distributed boundary forces and concentrated nodal forces. Because elements adjacent to a boundary node, each contribute to the nodal force there according to the equivalency criterion stated, the nodal force results from an averaging process. Moreover, the nodal force remains an "average value" regardless of the element size [47]. However, in the current model, the zero traction conditions at 
free edges are point-wisely satisfied and the ply refinement technique is implemented to capture the stress singularity. It should be also highlighted that although the approach has a high accuracy, none of the above results (both FEM and variational approach) are exact, due to the assumptions made in the formulation. It is noteworthy that the variational formulation has been derived without the assumption of having symmetry in the laminate with respect to the mid-plane. Therefore, preserving the symmetry of the laminate with high amount of ply refinement $(\mathrm{n}>8)$ shows the stability of the current formulation and of the associated software. It is a very important issue in assessing the quality of stress transfer models which is usually neglected and is achieved here using a nondimensional form for perturbation stresses (see Eqs. (8-12)) through-thickness direction.

In the third example, the accuracy of the approach concerning thermal residual stresses will be verified. To do so, an un-symmetric [0/90/45/-45] laminate (made of the material set \#1) under a uniform temperature change $\Delta T$, is considered. It is noted that for this loading cases (pure $\Delta T$ ), it is assumed that $N_{x x}=M_{x x}=0$ [31], therefore, a combination of applied axial strain and curvature for the case of unperturbed state is considered to have a pure thermal loading (Note: $\mathrm{N}_{\mathrm{yy}}=\mathrm{N}_{\mathrm{xy}}=\mathrm{M}_{\mathrm{yy}}=\mathrm{M}_{\mathrm{xy}}=0$ ). The laminate has the width $2 \mathrm{~W}=4 \mathrm{~h}$ where $\mathrm{h}=4 \mathrm{t}^{\mathrm{ply}}$ is the laminate thickness. The variational model is applied to this problem by dividing each ply into 7 elements of equal thickness where elements adjacent to interfaces are further subdivided in half, two times to ensure that the results are converged. The results are compared with FEM results reported in Ref. [31]. Figs. 4a and 4b show, respectively, the through-width distribution (close to free edges) of normalized out-of-plane normal $\frac{\sigma_{z z}}{\Delta T}$ and shear $\frac{\sigma_{y z}}{\Delta T}$ stresses, at different interfaces between plies in the laminate. Again, the general remark is that there is a very good accordance between the two sets of results. To further check the accuracy of the developed model, a $[0 / 90]_{\mathrm{s}}$ with the same material and geometrical properties as the last considered case ([0/90/45/-45] laminate) under a uniform temperature change, is also considered. It should be noted that for this loading case, it is assumed [32] that $\varepsilon_{x x}=\kappa_{x x}=0$. The results concerning this cross-ply laminate are compared with FEM results reported in Ref. [32]. The variational model is applied to this problem with the same ply refinement as the last considered case and also without ply refinement $(\mathrm{n}=1)$. Figs. 5a and 5b show, respectively, the through-width distribution of normalized out-of-plane normal $\frac{\sigma_{z z}}{\Delta T}$ and shear $\frac{\sigma_{y z}}{\Delta T}$ stresses, at the $0 / 90$ interface in the $[0 / 90]_{\mathrm{s}}$ laminate. It is worth mentioning that the variational approach, even without using a ply refinement $(\mathrm{n}=1)$ can predict the stress concentrations near free edges 
with a very good accuracy, confirming the high computational efficiency of the developed stress-based LW variational approach.

Next, the accuracy of the developed approach in predicting displacement fields will be assessed. A symmetric $[45 /-45]_{\mathrm{s}}$ laminate (made of the material set \#1) having the width $2 \mathrm{~W}=4 \mathrm{~h}$ under a uniform in-plane strain $\varepsilon_{x x}$, is considered. The variational model is applied to this problem by dividing each ply into 8 elements of equal thickness. Fig. 6a represents the through width distribution of normalized axial displacement $\left(\mathrm{u} / \mathrm{t}^{\mathrm{ply}} / \varepsilon_{\mathrm{xx}}\right)$ at upper external surface $(\mathrm{z}=\mathrm{h} / 2)$ of the $[45 /-45]_{\mathrm{s}}$ laminate. In addition, Fig. $6 \mathrm{~b}, 7 \mathrm{a}$ and $7 \mathrm{~b}$ depict, respectively, through thickness distribution of the normalized axial $\left(\mathrm{u} / \mathrm{t}^{\mathrm{ply}} / \varepsilon_{\mathrm{xx}}\right)$, normalized in-plane transverse $\left(\mathrm{v} / \mathrm{t}^{\mathrm{ply}} / \varepsilon_{\mathrm{xx}}\right)$ and normalized out-ofplane $\left(\mathrm{w} / \mathrm{t}^{\mathrm{ply}} / \varepsilon_{\mathrm{xx}}\right)$ displacements at free edge $(\mathrm{y}=\mathrm{W})$ of the $[45 /-45]_{\mathrm{s}}$ laminate. Some of the results are compared to the FEM results reported (whenever available) in Ref. [33] showing very good agreement.

In addition, the free-edge effect in thin-ply and typical ply composite laminates under bending loads will be compared. A $[0 / 90]_{\mathrm{s}}$ laminate with typical ply thickness $\left(\mathrm{t}_{\mathrm{ply}}=0.19 \mathrm{~mm}\right)$ and a $[0 / 90]_{5 \mathrm{~s}}$ laminate with thin plies $\left(\mathrm{t}_{\mathrm{ply}}=0.19 / 5=0.038 \mathrm{~mm}\right)$ having the width $2 \mathrm{~W}=20 \mathrm{~mm}$, made of material set $\# 2$, are considered under a uniform curvature $\kappa_{x x}$. In order to have the converged results for the laminate with typical plies [0/90]s, each ply is first divided into 5 elements with the same thickness and the elements adjacent to all interfaces have been successively divided in three, two times. For the laminate made of thin plies $[0 / 90]_{5 s}$, each ply is first divided into 3 elements with the same thickness and the elements adjacent to all interfaces have been divided in half. In total, 44 and 98 ply elements are used to model precisely interlaminar stress transfer in typical and thin-ply laminates, respectively. Fig. 8a depicts the through-thickness variation of the normalized interlaminar out-of-plane normal $\left(\frac{\sigma_{z z}}{\kappa_{x x} h}\right)$ stresses very close to the free edge $(\mathrm{y}=0.998 \mathrm{~W})$ for both laminates with thin and typical plies. Fig. $8 \mathrm{~b}$ also represents the distribution of the normalized interlaminar out-of-plane shear $\left(\frac{\sigma_{y z}}{\kappa_{x x} h}\right)$ stresses through the width at $0 / 90$ interface for both typical $(\mathrm{z}=0.19 \mathrm{~mm})$ and thin-ply $(\mathrm{z}=0.29766 \mathrm{~mm}$, interface with highest interlaminar stresses) laminates.

Moreover, Fig. 9 compares the through-thickness variation of the normalized transverse displacement $\left(\frac{v}{\kappa_{x x} h^{2}}\right)$ of typical and thin-ply laminates at the location of the free edge $(y=W)$. It is seen that $3 \mathrm{D}$ stress concentrations due to 
the free-edge effect in thin-ply laminates are remarkably less than typical laminates. It can be clearly seen in Fig. 8b that when the ply thickness decreases, the size of edge effect remarkably decreases. Moreover, it can be also seen that thin-ply laminates are deformed much less than typical ply laminates when facing stress concentrations like free-edge effect. The results presented in Figs. 8 and 9 show that reducing the ply thickness can lead to dramatic improvements in the interlaminar stress transfer performance of laminates. It can then lead to a significant delayed damage growth and a longer fatigue life $[48,49]$. It should be mentioned that the use of numerical methods (e.g. FEM) when solving the free-edge effects in composite laminates with many plies (e.g. thin-ply laminates) will be exceedingly challenging and tedious due to the complexity of the required meshes near free edges and interfaces between the plies.

Finally, in order to estimate the approximate size of the edge-effect (width of the region in which severe perturbation of three-dimensional stresses occurs), an anti-symmetric angle-ply laminate [-45/45] under only a uniform axial strain $\varepsilon_{x x}\left(\right.$ while $\kappa_{x x}$ ), made of material set \#2, with two different widths ( $2 \mathrm{~W}=8 \mathrm{~h}$ (finite width) and $2 \mathrm{~W}=1000 \mathrm{~h}$ (infinite width)) where $\mathrm{h}=2 \mathrm{t}^{\mathrm{ply}}$, is considered to study the extent of edge-effect. The through width distribution of the normalized interlaminar shear $\left(\frac{\sigma_{x z}}{\varepsilon_{x x} E_{A}}\right)$ stresses at the interface between $-45 / 45$ plies for the laminates with finite and infinite widths, is shown in Fig. 10a. The through width distribution of the normalized in-plane axial $\left(\frac{\sigma_{x x}}{\varepsilon_{x x} E_{A}}\right)$ stresses at the upper external surface, is shown in Fig. 10b. In addition, Figs. 11a and 11b, respectively, show the through width distribution of the normalized axial $\left(\mathrm{u} / \varepsilon_{\mathrm{xx}} / \mathrm{W}\right)$ and transverse $\left(\mathrm{v} / \varepsilon_{\mathrm{xx}} / \mathrm{W}\right)$ displacements at the upper external surface for both laminates with finite and infinite widths. It can be clearly seen that well way from the free edges, the results of both laminates with finite and infinite width, are in perfect agreement showing the results of CLPT. In these figures, the approximate size of the edge-effect can be seen although in general, it depends on the laminate lay-up, material properties, laminate width to thickness ratio $(2 \mathrm{~W} / \mathrm{h})$, etc.

It is worth mentioning that unlike the current approach based on an assumed form for the through-thickness variations of the in-plane stress fields, some authors have tried to solve exactly the three-dimensional differential equations of elasticity based on the assumption of arbitrary shape functions for the displacement components through both the in-plane and out-of-plane coordinates. However, these approaches are still restricted to cross-ply laminates with free-edges [50] and general laminates with simply-supported boundary conditions [51, 52] without 

stresses.

It should be also noted that the free edges might not always be straight such as for holes and cutouts in laminates. A generic variational procedure for laminates with circular holes under in-plane loads is developed [53, 54] in the cylindrical coordinate system which can be used to study free-edge effect in more complex geometries.

\section{Conclusion}

The following conclusions have been drawn from the paper:

1- A novel stress-based variational model has been developed to determine accurately a complete solution for both stress and displacement fields in laminate strips containing straight free edges with general lay-ups (possibly unsymmetrical laminates and made of thin-plies) under in-plane, bending and thermal loading.

2- By partitioning the total stresses in a composite with free edges into initial (without free edges) and perturbation stresses and using the principle of minimum complementary energy, the free-edge stress transfer problem has been reduced to a set of homogeneous differential equations that can be solved.

3- The obtained stress and displacement fields satisfy exactly the stress equilibrium equations, strain-stress relations (either exactly or in an average sense) together with all boundary and continuity conditions.

4- The results are in excellent agreement with the available refined FEM results. Moreover, the approach is superior to FEM in terms of computational efficiency and accuracy.

5- It has been noted that the Pagano's and McCartney's solutions [28-31] can also be derived from a fully stressbased variational approach.

6- The generalized plane bending theory $[30,31]$ has been extended to analyze laminates with arbitrary stacking sequence. The findings can be used to extend the versatility of the available ply cracking models.

7- The developed methodology with capability of modeling many plies can be the basis of good design tools to predict thickness, lay-up, material property and geometrical effects on damage initiation in thin-ply composite laminates with free edges.

8- The methodology used in this paper for thermally induced residual stresses can be easily extended to deal with the residual stresses caused by humidity. 

three-dimensional stresses occurs) decreases when the ply thickness decreases.

\section{References}

[1]- Farge L, Ayadi Z, Varna J. Optically measured full-field displacements on the edge of a cracked composite laminate. Composites: Part A 2008; 39:1245-52.

[2]- Okabe T, Imamura H, Sato Y, Higuchi R, Koyanagi J, Talreja R. Experimental and numerical studies of initial cracking in CFRP cross-ply laminates. Composites: Part A 2015; 68: 81-9.

[3]- Kumagai Y, Onodera S, Nagumo Y, Okabe T, Yoshioka K. Multiscale modeling of free surface effect on crack formation in unidirectional off-axis laminates. Composites: Part A 2017; 98:136-46.

[4]- Cater CR, Xiao X, Goldberg RK, Gong X. The influence of interlaminar microstructure on micro-cracking at laminate free edge, Composites: Part A (2018), doi: https://doi.org/10.1016/j.compositesa.2018.04.007.

[5]- Fotouhi M, Jalalvand M, Wisnom M. Notch insensitive orientation dispersed pseudo-ductile thin-ply carbon/glass hybrid laminates. Composites Part A 2018; 110:29-44.

[6]- Puppo AH, Evensen HA. Interlaminar shear in laminated composites under generalized plane stress. J Compos Mater 1970;4:204-20.

[7]- Becker W. Closed-Form Solution for the Free-Edge Effect in Cross- Ply Laminates. Compos. Struct 1993; 26; $39-45$.

[8]- Pipes RB, Pagano N. Interlaminar Stresses in Composite Laminates-An Approximate Elasticity Solution. ASME J. Appl. Mech 1974; 4: 668-72.

[9]- Kimpara I, Kageyama K, Suzuki K. Finite element stress analysis of interlayer based on selective layerwise higher-order theory. Composites: Part A 1998; 29A:1049-56.

[10]- Tahani M, Nosier A. Free Edge Stress Analysis of General Cross-Ply Composite Laminates Under Extension and Thermal Loading. Compos. Struc 2003; 60:91-103.

[11]- Kassapoglou C. Determination of Interlaminar Stresses in Composite Laminates under Combined Loads. J Reinforced Plastics and Composites 1990; 9: 33-58.

[12]- Mittelstedt C, and Becker W. Free-Edge Effects in Composite Laminates. ASME Appl. Mech. Rev 2007; 60: $217-45$. 
[13]- Nosier A, Bahrami A. Interlaminar stresses in antisymmetric angle-ply laminates. Composite Structures 2007; 78: $18-33$.

[14]- Peng B, Goodsell J, Pipes RB, Yu W. Generalized Free-Edge Stress Analysis Using Mechanics of Structure Genome. ASME J. Appl. Mech 2016; 83: 101013-7.

[15]- Hashin Z. Analysis of cracked laminates: a variational approach. Mech Mater 1985; 4:121-36.

[16]- Nairn JA. Hu S. The initiation and growth of delaminations induced by matrix microcracks in laminated composites. International Journal of Fracture 1992; 57: 1-24.

[17]- Varna J, Berglund LA. A model for prediction of the transverse cracking strain in cross-ply laminates. J. Reinf. Plast. Compos 1992; 11: 708-28.

[18]- Li S, Hafeez F. Variation-based cracked laminate analysis revisited and fundamentally extended. Int J Solids and Structures 2009; 46: 3505-15

[19]- Hajikazemi M, Sadr MH. A Variational model for stress analysis in cracked laminates with arbitrary symmetric lay-up under general in-plane loading. Int. J. Solids Struct 2014; 51: 516-29.

[20]- Hajikazemi M, Sadr MH, Talreja R. Variational analysis of cracked general cross-ply laminates under bending and biaxial extension. Int J Damage Mech 2015; 24:582-624.

[21]- Hajikazemi M, Sadr MH, H. Hosseini-Toudeshky, B. Mohammadi. Thermo-elastic constants of cracked symmetric laminates: a refined variational approach. Int J Mech Sci 2014; 89: 47-57.

[22]- Hajikazemi M, McCartney LN. Comparison of Variational and Generalized Plane Strain approaches for matrix cracking in general symmetric laminates. Int J Damage Mech, First published date: January-05-2017, DOI:10.1177/1056789516685381.

[23]- Hajikazemi M, McCartney LN, Van Paepegem W, Sadr MH. Theory of variational stress transfer in general symmetric composite laminates containing non-uniformly spaced ply cracks. Composites Part A 2018;107:374-386

[24]- Kassapoglou C, Lagace P. An Efficient Method for the Calculation of Interlaminar Stresses in Composite Materials. ASME J. Appl. Mech 1986; 53: 744-50.

[25]-Webber JPH, Morton SK. An Analytical Solution for the Thermal Stresses at the Free Edges of Laminated Plates. Compos. Sci. Technol 1993: 46:175-185.

[26]- Lin CC, Hsu CY, Ko CC. Interlaminar Stresses in General Laminates With Straight Free Edges. AIAA J. $1995 ; 33: 1471-1476$. 
[27]-Rose CA, Herakovich CT. An approximate solution for interlaminar stresses in composite laminates. Composites Eng 1993; 3: 271-85.

[28]- Hajikazemi M, Sadr MH, Varna J. Analysis of cracked general cross-ply laminates under general bending loads: A variational approach. J Comp Mat 2016;51:3089-3109.

[29]- Joosten MW, Agius S, Hilditch T, Wang C. Effect of residual stress on the matrix fatigue cracking of rapidly cured epoxy/anhydride composites. Composites: Part A 2017; 101:521-28.

[30]- Saeedi N, Sab K, Caron JF. Delaminated multilayered plates under uniaxial extension. Part II: Efficient layerwise mesh strategy for the prediction of delamination onset. Int J solids \& Structures 2012;49:3727-40.

[31]- Andakhshideh A, Tahani M. Free-edge stress analysis of general rectangular composite laminates under bending, torsion and thermal loads. Euro J Mechanics A/Solids 2013 42: 229-40.

[32]- Nguyen VT, Caron JF. Finite element analysis of free-edge stresses in composite laminates under mechanical an thermal loading. Composites Science and Technology 2009; 69; 40-49.

[33]- Wang ASD, Crossman FW. Some New Results on Edge Effect in Symmetric Composite Laminates. J Comp Mater 1977; 11: 92-106.

[34]- Pagano NJ. Stress Fields in Composite Laminates. Int J Solids \& Struc 1978; 14:385-400.

[35]- Schoeppner GA, Pagano NJ. Stress fields and energy release rates in cross-ply laminates. International Journal of Solids and Structures 1998; 35:1025-55.

[36]- McCartney LN and Pierse S. Stress transfer mechanics for multiple ply laminates subject to bending. NPL Report 1997 CMMT(A) 55.

[37]- McCartney LN. Predicting ply crack formation in cross-ply laminates subject to generalised plane bending. In: Procedings 6th international conference on deformation and fracture of composites, Manchester, 4-5 April 2001, pp.57-66.

[38]- McCartney LN. Model to predict effects of triaxial loading on ply cracking in general symmetric laminates. Composites Science and Technology 2000; 60: 2255-2279.

[39]- Hajikazemi M, Van Paepegem W. A variational model for free-edge interlaminar stress analysis in general symmetric and thin-ply composite laminates. Comp Struc 2018;184:443-51.

[40]- Nairn JA. Exact and variational theorems for fracture mechanics of composites with residual stresses, tractionloaded cracks, and imperfect interfaces. Int J Fracture 2000; 105: 243-71. 

International Journal of Engineering Science 1970; 8: 5-18.

[42]- McCartney LN. Physically based damage models for laminated composites. Proceedings of Institution of Mechanical Engineers, Part L: J Mater: Design and Applications 2003; 217;163-99.

[43]- Takeda N, McCartney N, Ogihara S. The application of a ply-refinement technique to the analysis of microscopic deformation in interlaminar-toughened laminates with transverse cracks. Composites Science and Technology 2000; 60: 231-40.

[44]- Wang SS, Choi I. Boundary-layer effects in composite laminates. Part 1- Free-edge stress singularities. ASME J. Appl. Mech 1982; 49: 541-548.

[45]- Wang SS, Choi I. Boundary-layer effects in composite laminates. Part 2- Free-edge stress solutions and basic characteristics. ASME J. Appl. Mech 1982; 49: 549-560.

[46]- Tong P, Pian THH. On the convergence of the finite element methods for problems with singularity. International Journal of Solids and Structures 1973; 9: 313-21.

[47]- Bauld NR, Goree JG, Tzeng L-S. A comparison of finite-difference and finite-element methods for calculating free edge stresses in composites. Computers and Structures 1985; 20:897-914.

[48]- Frossard G, Cugnoni J, Gmur T, Botsis J. Mode I interlaminar fracture of carbon epoxy laminates: Effects of ply thickness. Composites Part A 2016; 91:1-8.

[49]- Amacher R, Cugnoni J, Botsis J, Sorensen L, Smith W, Dransfeld C. Thin ply composites: Experimental characterization and modeling of size-effects. Composites Science and Technology 2014; 101:121-132.

[50]- Savoia M, Reddy JN. A variational approach to three-dimensional elasticity solutions of laminated composite plates. ASME J. Appl. Mech 1992; 59: 166-175.

[51]- Liang W-Y, Ju S-H, Tarn J-Q. Analytic determination of stress fields in cross-ply symmetric composite laminates. International Journal of Solids and Structures 2016; (94-95): 87-99.

[52]- Demasi L, Three-dimensional closed form solutions and $\infty 3$ theories for orthotropic plates. Mechanics of Advanced Materials and Structures 2010; 17:20-39.

[53]-Saeger KJ, An efficient semi-analytic method for the calculation of intetlaminar stresses around holes. $\mathrm{PhD}$ Thesis-Massachusetts Institute of Technology, Dept. of Aeronautics and Astronautics, 1989. http://hdl.handle.net/1721.1/39030 

California, April 6-8, 1987. pp. 36-43.

\section{Appendix A.}

The result of integration over z, in Eq. (17) based on the independent unknown perturbation stress functions is written in Eq. (18) where the functional $\mathrm{F}$ will be defined, as follows:

$$
\begin{aligned}
& F\left(y,\{p\},\left\{p^{*}\right\},\left\{p^{\prime \prime}\right\},\left\{p^{*^{* \prime}}\right\},\{q\},\left\{q^{*}\right\},\left\{p^{\prime}\right\},\left\{p^{*^{\prime}}\right\},\left\{q^{\prime}\right\},\left\{q^{*^{*}}\right\}\right)=
\end{aligned}
$$

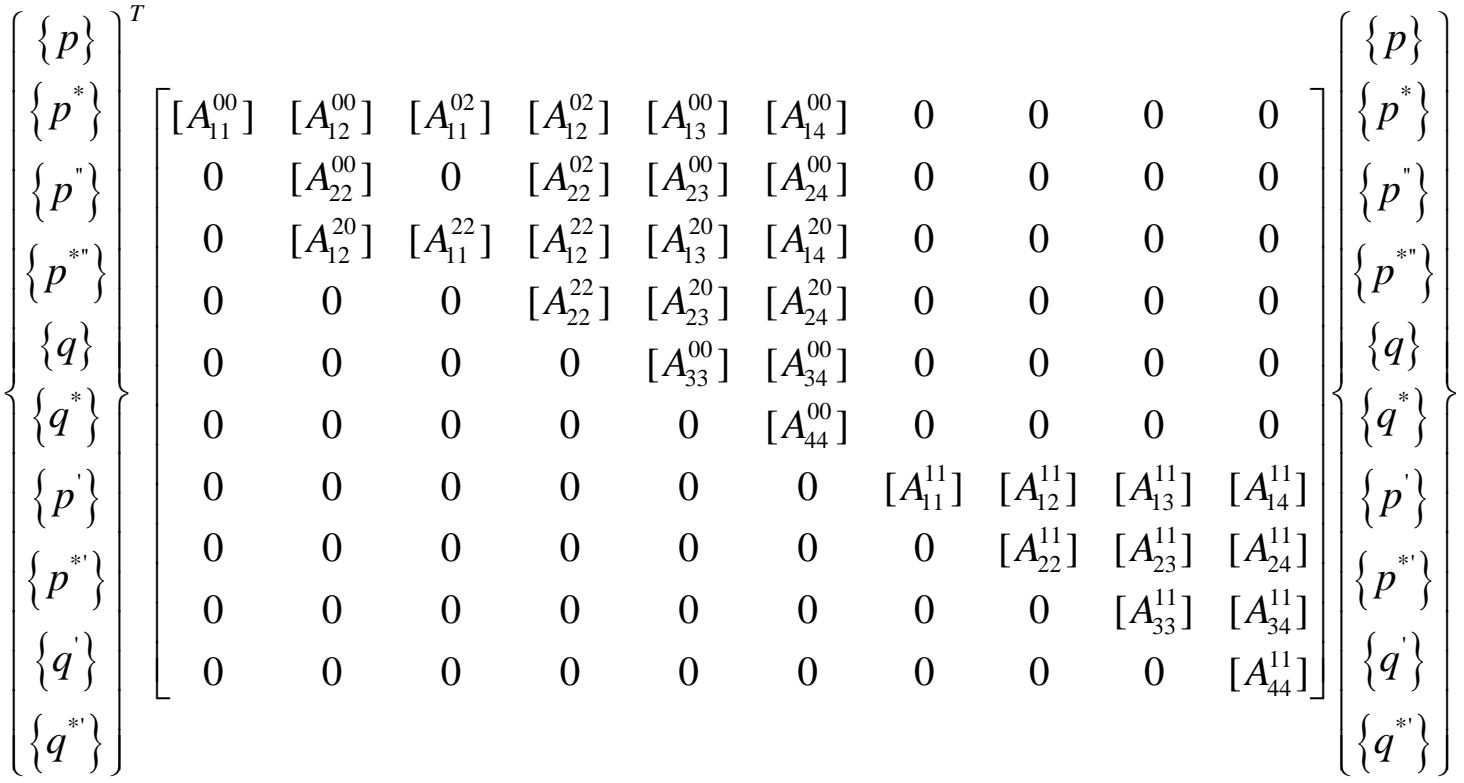

where the coefficient matrices $\left[A_{11}^{00}\right]_{(N-1) \times(N-1)}$, etc., with the superscripts corresponding to the order of derivatives and the subscripts corresponding to independent unknown functions involved, can be easily evaluated analytically in terms of ply properties.

\section{Appendix B.}

The $\left[\mathrm{T}_{\mathrm{i}}\right]$ matrices defined in Eqs. (23)-(26), $\mathrm{i}=1 \ldots 23$, will be defined in terms of $\left[A_{11}^{00}\right]$ matrices, etc., as follows: 


\section{Appendix C.}

The reduced form of strain/stress relations are defined by Eqs. (33)-(35) where the reduced compliances have the following forms:

$$
\begin{aligned}
& \bar{S}_{22}^{i}=S_{22}^{i}-\frac{S_{12}^{i 2}}{S_{11}^{i}}, \bar{S}_{23}^{i}=S_{23}^{i}-\frac{S_{12}^{i} S_{13}^{i}}{S_{11}^{i}}, \bar{S}_{26}^{i}=S_{26}^{i}-\frac{S_{12}^{i} S_{16}^{i}}{S_{11}^{i}}, \\
& \bar{S}_{33}^{i}=S_{33}^{i}-\frac{S_{13}^{i 2}}{S_{11}^{i}}, \bar{S}_{36}^{i}=S_{36}^{i}-\frac{S_{13}^{i} S_{16}^{i}}{S_{11}^{i}}, \bar{S}_{66}^{i}=S_{66}^{i}-\frac{S_{16}^{i}}{S_{11}^{i}}, \\
& \bar{\alpha}_{2}^{i}=\alpha_{2}^{i}-\frac{S_{12}^{i} \alpha_{1}^{i}}{S_{11}^{i}}, \bar{\alpha}_{3}^{i}=\alpha_{3}^{i}-\frac{S_{13}^{i} \alpha_{1}^{i}}{S_{11}^{i}}, \bar{\alpha}_{6}^{i}=\alpha_{6}^{i}-\frac{S_{16}^{i} \alpha_{1}^{i}}{S_{11}^{i}},
\end{aligned}
$$

\section{Appendix D.}

The displacement fields must satisfy the continuity conditions at the interface between the plies:

$$
u_{i}=u_{i+1}, \quad v_{i}=v_{i+1}, \quad w_{i}=w_{i+1}, \quad \text { on } \quad z=z_{i} \quad i=1, \ldots, N-1 .
$$

On substituting $z=z_{i}\left(\zeta_{i}=1\right)$ in (36) and considering Eq. (D.1) $)_{3}$, the following recurrence relation is derived for the functions $\Delta W_{i}(y)=W_{i}(y)-W_{N}(y)$, for $\mathrm{i}=1 \ldots \mathrm{N}-1$ :

$$
\begin{aligned}
& \Delta W_{i}(y)=\Delta W_{i+1}(y)-\frac{1}{6} h_{i+1}^{2} \bar{S}_{33}^{i+1} p_{i+1}^{* * 1}(y)-h_{i}^{2} \bar{S}_{33}^{i}\left(\frac{1}{8} p_{i}^{\prime \prime}(y)-\frac{1}{2} F_{1}^{i^{\prime}}(y)+\frac{1}{h_{i}} F_{3}^{i}(y)\right) \\
& -\left(\bar{S}_{23}^{i} p_{i}^{*}(y)+\bar{S}_{36}^{i} q_{i}^{*}(y)\right)-\frac{1}{2}\left(\bar{S}_{23}^{i} p_{i}(y)+\bar{S}_{36}^{i} q_{i}(y)\right)-h_{i} \int_{0}^{1} \varepsilon_{z z}^{0(i)} d \zeta, \text { where } \Delta W_{N}(y) \equiv 0 .
\end{aligned}
$$


Similarly, on substituting $z=z_{i}\left(\zeta_{i}=1\right)$ in (37) and considering Eq. (D.1 $)_{2}$, the following recurrence relation is derived for the functions $\Delta V_{i}(y)=V_{i}(y)-V_{N}(y)$, for $\mathrm{i}=1 \ldots \mathrm{N}-1$ :

$$
\begin{aligned}
& \Delta V_{i}(y)=\Delta V_{i+1}(y)-\frac{1}{24} h_{i+1}^{3} \bar{S}_{33}^{i+1} p_{i+1}^{* *^{\prime \prime \prime}}(y)+\frac{h_{i}^{2} \bar{S}_{33}^{i}}{24}\left(\frac{11}{5} p_{i}^{\prime \prime \prime}(y)-8 F_{1}^{i^{\prime \prime}}(y)+\frac{12}{h_{i}} F_{3}^{i^{\prime}}(y)\right) \\
& -\frac{h_{i}}{2}\left(p_{i}^{* \prime}(y)\left(2 S_{44}^{i}-\left(\bar{S}_{23}^{i}+S_{44}^{i}\right)\right)+q_{i}^{* \prime}(y)\left(2 S_{45}^{i}-\left(\bar{S}_{36}^{i}+S_{45}^{i}\right)\right)-2 S_{45}^{i} F_{2}^{i}(y)-2 S_{44}^{i} F_{1}^{i}(y)\right) \\
& -\frac{h_{i}}{2}\left(p_{i}^{\prime}(y)\left(S_{44}^{i}-\frac{1}{3}\left(\bar{S}_{23}^{i}+S_{44}^{i}\right)\right)+q_{i}^{\prime}(y)\left(S_{45}^{i}-\frac{1}{3}\left(\bar{S}_{36}^{i}+S_{45}^{i}\right)\right)\right)+h_{i} W_{i}^{\prime}(y), \text { where } \Delta V_{N}(y) \equiv 0 .
\end{aligned}
$$

Similarly, on substituting $z=z_{i}\left(\zeta_{i}=1\right)$ in (38) and considering Eq. (D.1) $)_{1}$, the following recurrence relation is derived for the functions $\Delta U_{i}(y)=U_{i}(y)-U_{N}(y)$, for $\mathrm{i}=1 \ldots \mathrm{N}-1$ :

$$
\begin{aligned}
& \Delta U_{i}(y)=\Delta U_{i+1}(y)-\frac{h_{i}}{3}\left(S_{45}^{i} p_{i}^{\prime}(y)+S_{55}^{i} q_{i}^{\prime}(y)\right)-\frac{h_{i}}{2}\left(S_{45}^{i} p_{i}^{*^{*}}(y)+S_{55}^{i} q_{i}^{* \prime}(y)\right) \\
& +h_{i}\left(S_{45}^{i} F_{1}^{i}(y)+S_{55}^{i} F_{2}^{i}(y)\right), \text { where } \Delta U_{N}(y) \equiv 0 .
\end{aligned}
$$

The functions $\Delta W_{N}(y)$ and $\Delta V_{N}(y)$ defined by (D.2) and (D.3), can be calculated using through-thickness average and through-thickness moment average of the Eq. (33). Moreover, the function $\Delta U_{N}(y)$ defined (D.4), can be calculated using through-thickness average of the Eq. (35). 


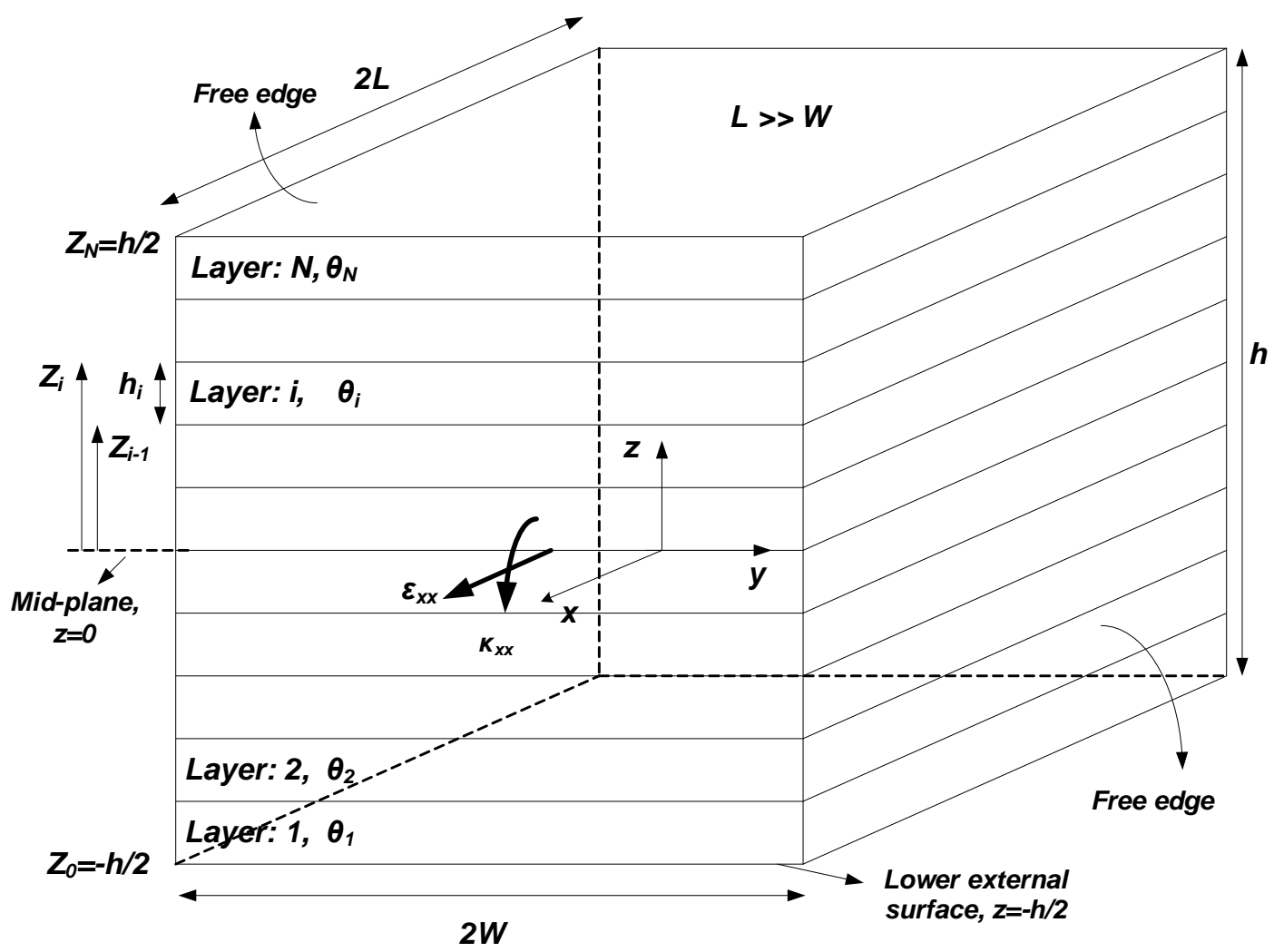

Fig. 1. A general laminate with arbitrary stacking sequence with two straight free edges. (Note: the origin of the coordinate system is located at the center of the laminate but there is no need to have an interface located at the mid-plane) 


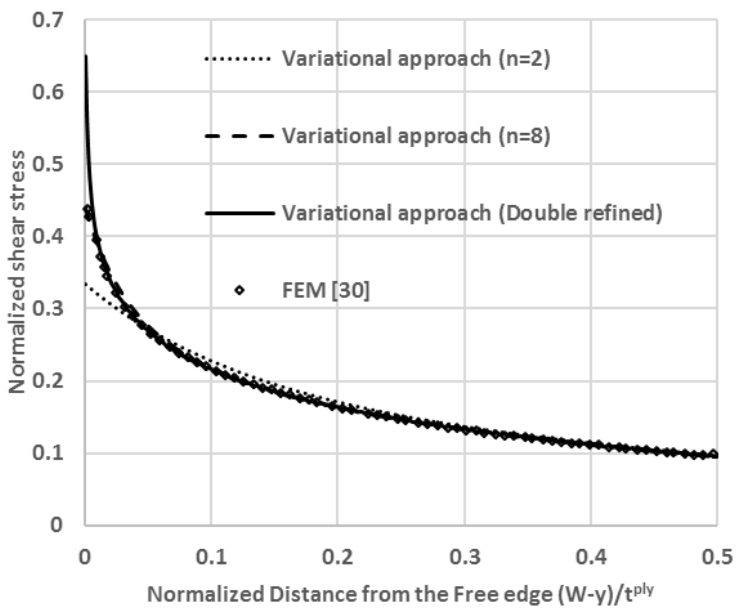

(a), $\theta=10^{0}$

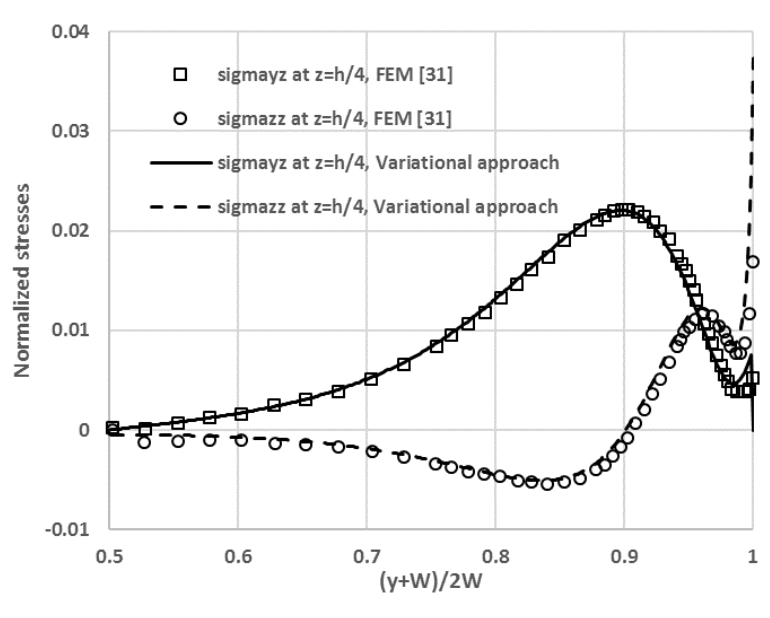

(b)

Fig. 2. Transverse (through-width) distribution of the normalized interlaminar normal $\sigma_{z z}$ and shear $\sigma_{y z}$ stresses at a) the laminate mid-plane $(\mathrm{z}=0)$ and $\mathrm{b})$ the upper interface $(\mathrm{z}=\mathrm{h} / 4)$ of a [0/90/45/90] laminate under pure bending loading.

Fig. 3. Transverse (through-width) distribution of the normalized interlaminar shear $\sigma_{x z}$ stress very close to the free edge at $\theta /-\theta$ interface of $[ \pm \theta]_{s}$ laminate under $\varepsilon_{x x}$. 


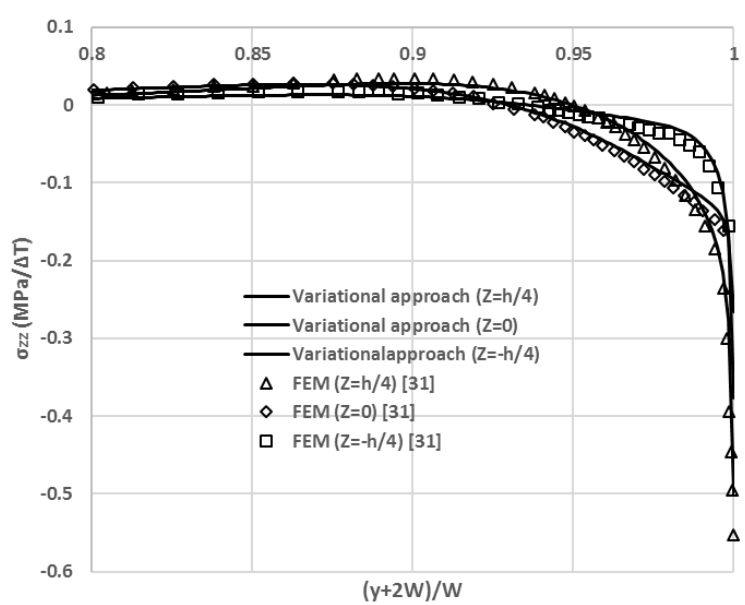

(a)

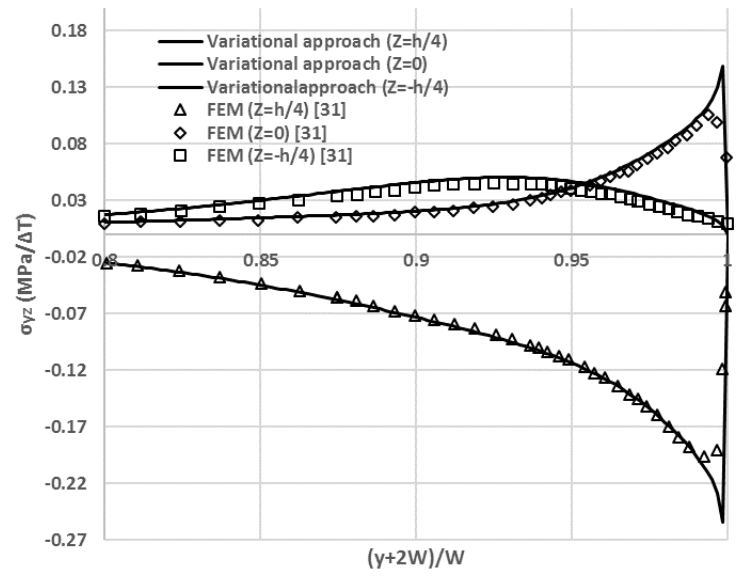

(b)

Fig. 4. Transverse (through-width) distribution of the normalized interlaminar a) normal $\sigma_{z z}$ and b) shear $\sigma_{y z}$ stresses at different interfaces between the plies in a [0/90/45/-45] laminate under a uniform temperature change $\Delta T$

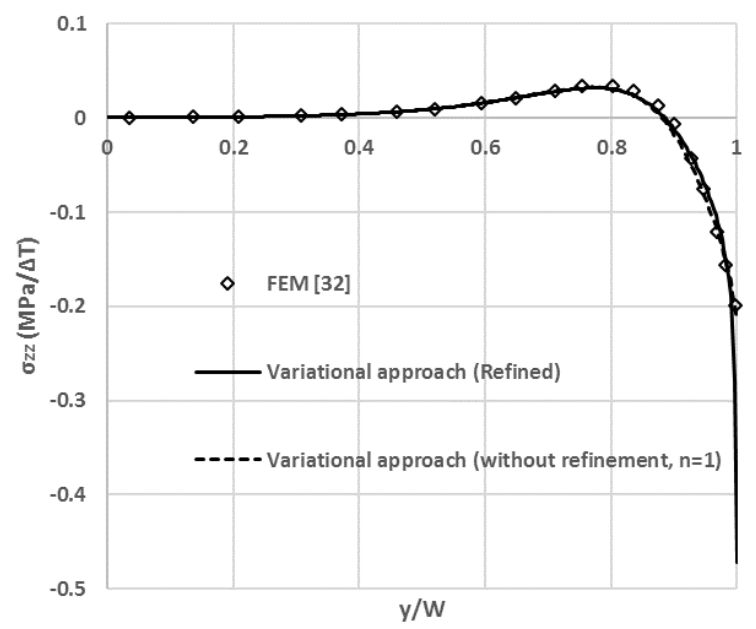

(a)

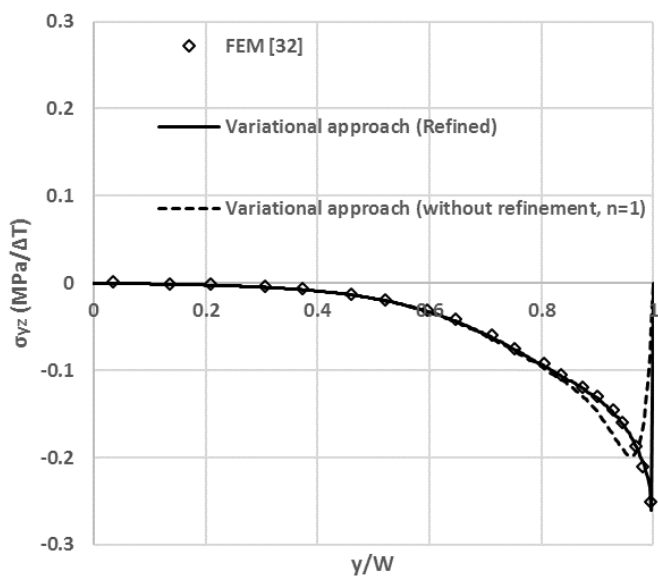

(b)

Fig. 5. Transverse (through-width) distribution of the normalized interlaminar a) normal $\sigma_{z z}$ and b) shear $\sigma_{y z}$ 
stresses at the $0 / 90$ interface in a $[0 / 90]_{\mathrm{s}}$ laminate under a uniform temperature change $\Delta T$.

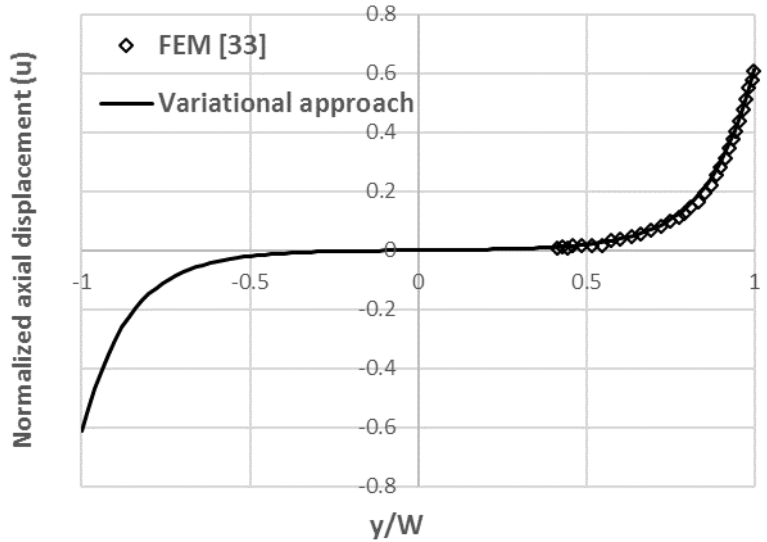

(a)

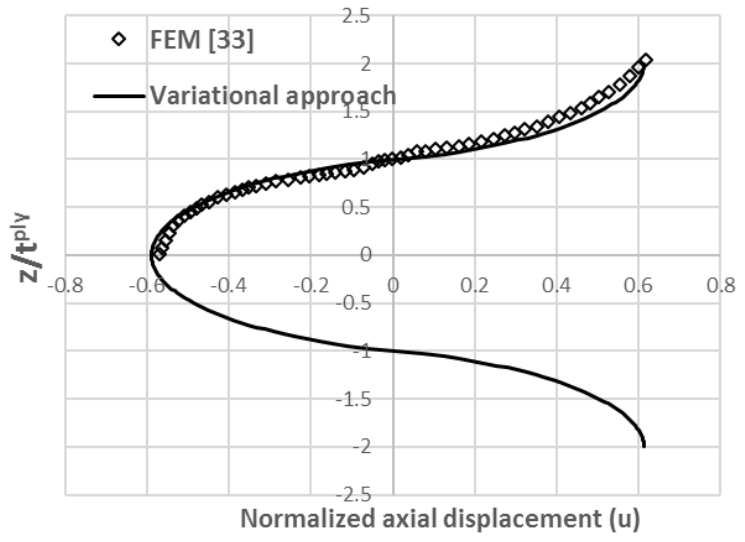

(b)

Fig. 6. a) Transverse (through-width) distribution of the normalized axial displacement (u) at top external surface $(\mathrm{z}=\mathrm{h} / 2)$ from edge to edge. $\mathrm{b})$ Through thickness distribution of the normalized axial displacement $(\mathrm{u})$ at free edge $(\mathrm{y}=\mathrm{W})$ of $[45 /-45]_{\mathrm{s}}$ laminate under $\varepsilon_{\mathrm{xx}}$.

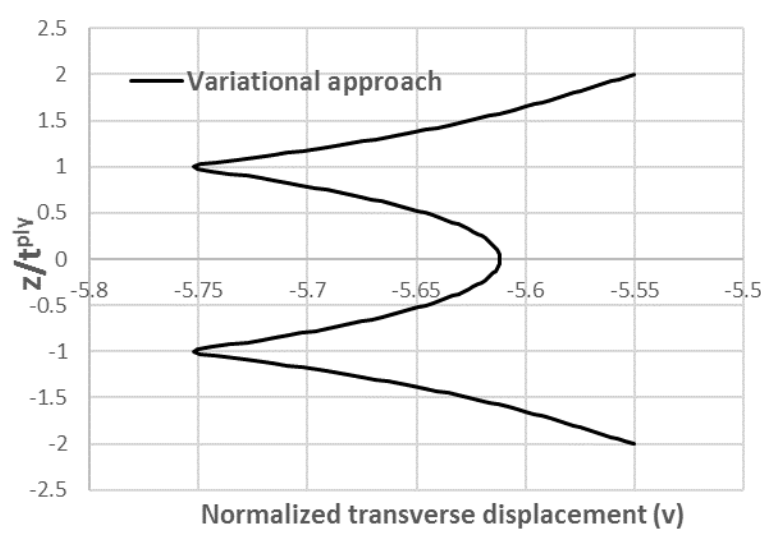

(a)

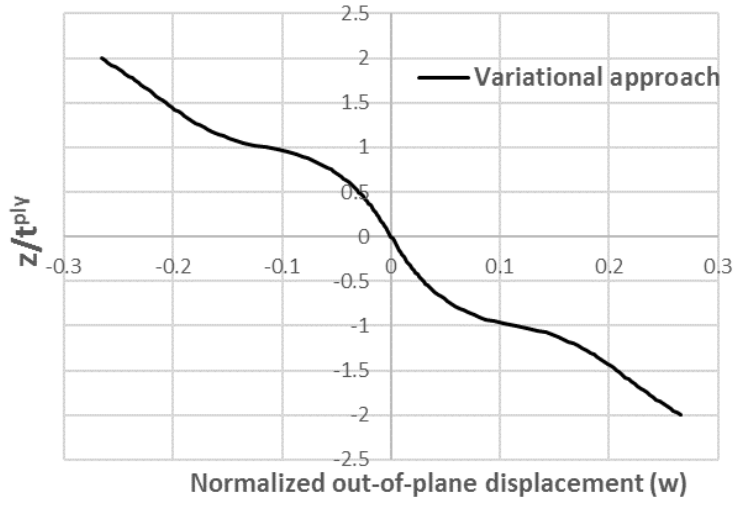

(b)

Fig. 7. Through thickness distribution of a) the normalized transverse displacement (v) b) the normalized out-ofplane displacement $(\mathrm{w})$ at free edge $(\mathrm{y}=\mathrm{W})$ of $[45 /-45]_{\mathrm{s}}$ laminate under $\varepsilon_{\mathrm{xx}}$. 


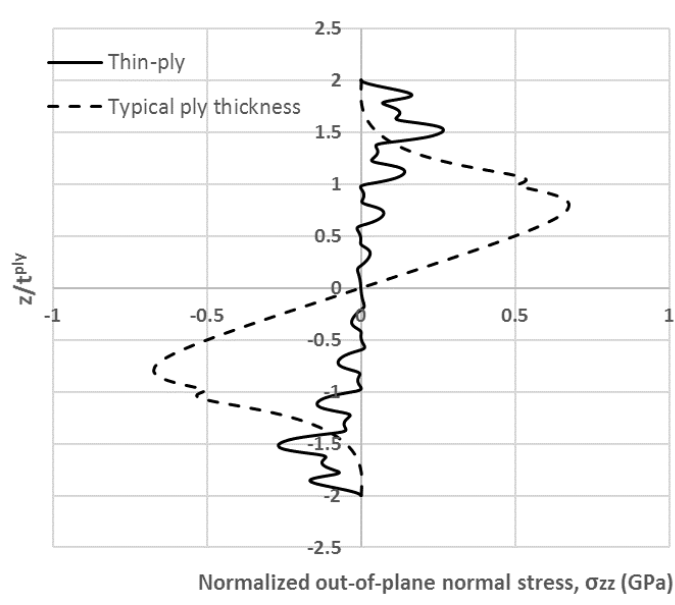

(a)

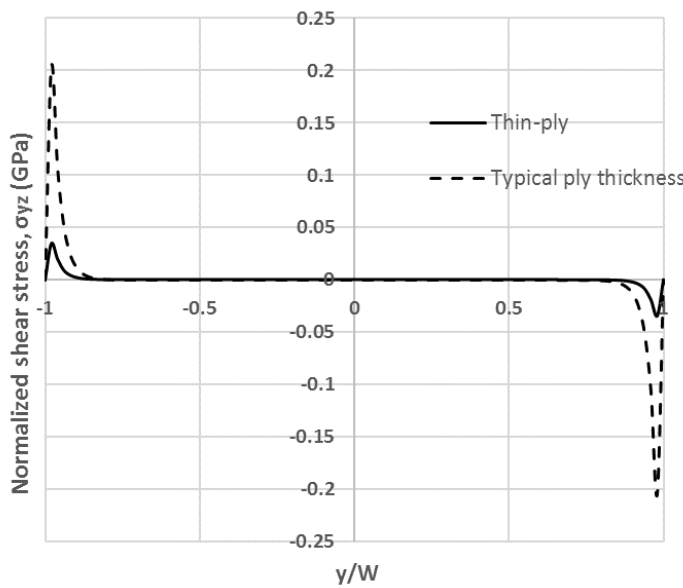

(b)

Fig. 8. a) Through thickness distribution of normalized interlaminar normal stress $\sigma_{\mathrm{zz}}$ very close to the free edge $(\mathrm{y}=0.998 W)$. b) Distribution of normalized shear stress $\sigma_{\mathrm{yz}}$ at $0 / 90$ interface across the width.

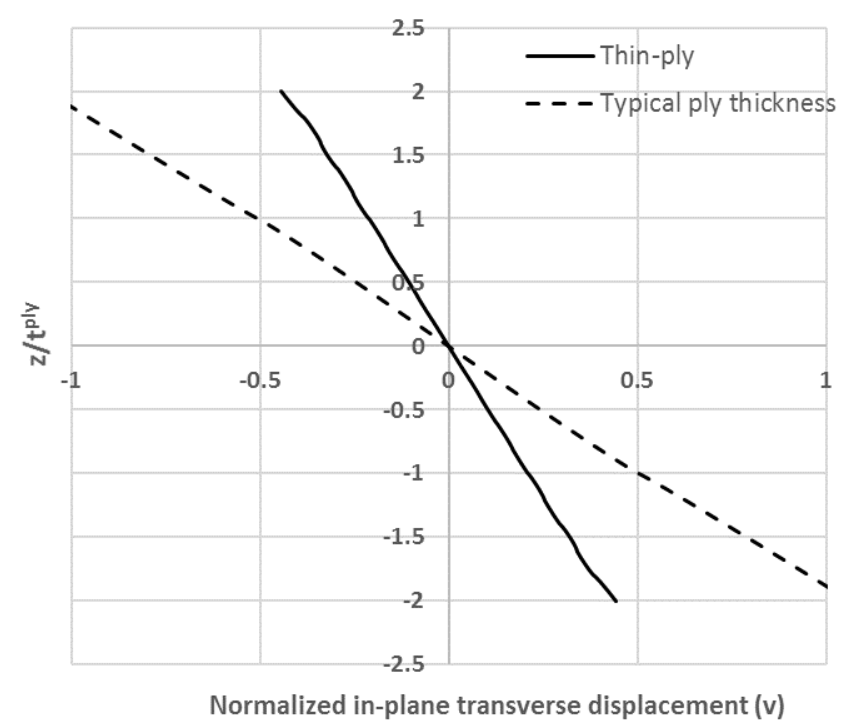

Fig. 9. Through thickness distribution of normalized interlaminar transverse displacement $(v)$ at the free edge $(y=$ W). 


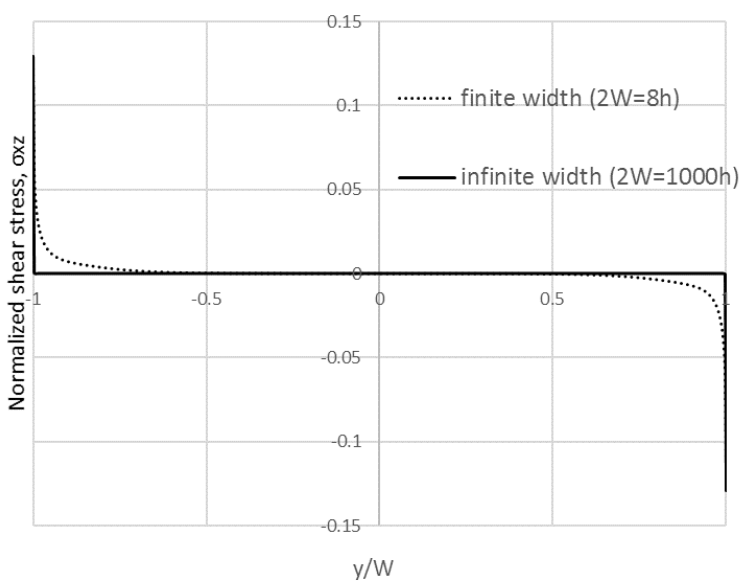

(a)

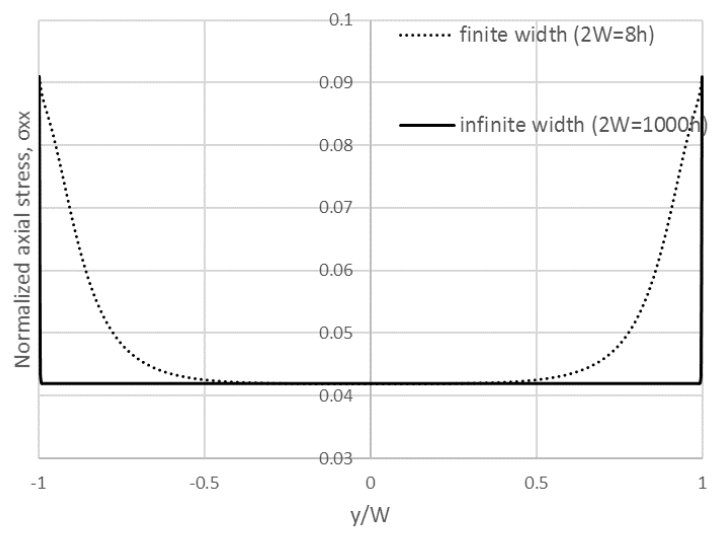

(b)

Fig. 10. a) Through width distribution of normalized interlaminar shear stress $\sigma_{x z}$ at the $-45 / 45$ interface. b) Through width distribution of normalized in-plane axial stress $\sigma_{x x}$ at the upper external surface.

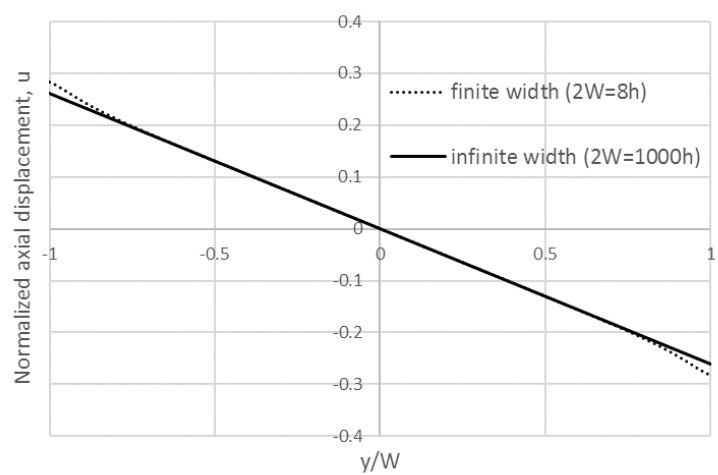

(a)

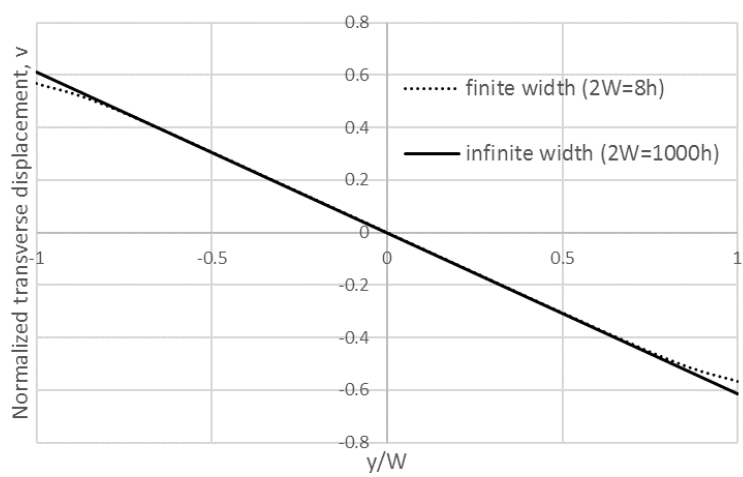

(b)

Fig. 11. Through width distribution of the normalized a) axial $u$ and b) transverse $v$ displacements at the upper external surface. 